\title{
LOS TESOROS DE LOS MALLKU DE POCONA Y TOTORA EN EL SIGLO XVI
}

\author{
THE TREASURES OF THE MALLKU OF POCONA AND TOTORA \\ IN THE SIXTEENTH CENTURY
}

\author{
Mercedes del Río ${ }^{1}$
}

\begin{abstract}
Este artículo ofrece un análisis etnohistórico de un centro cocalero ubicado en la frontera oriental del Tawantinsuyu durante el siglo XVI. Los inkas organizaron un archipiélago multiétnico en los valles de Pocona y Totora (Charcas) destinado a la defensa de la frontera y al cultivo estatal de la hoja de coca, el cual se prolongó con las mismas funciones en el período colonial. El objetivo de este trabajo apunta a demostrar que las autoridades étnicas coloniales de esta porción fronteriza atesoraban prestigiosos símbolos de autoridad que aludían al tiempo del inka y reforzaban sus jerarquías coloniales. Especialmente, estos tesoros activaban la memoria de sus ancestros quienes habían sido "capitanes del inka", organizaron la mano de obra en los cocales estatales y las actividades ceremoniales vinculadas al ciclo agrícola y a la defensa militar.
\end{abstract}

Palabras claves: etnohistoria andina, coca, curacas, frontera, Pocona y Totora, iconografía precolombina y colonial.

This article presents an etnohistorical analysis of a coca production zone on the eastern frontiers of the Tawantinsuyu during the 16th century. The Inkas had organized a multiethnic archipelago in the valleys of Pocona and Totora (Charcas) in order to defend the frontier and cultivate coca for the State; this continued during the early Colonial Period. The paper shows that colonial ethnic leaders in these frontier valleys hoarded prestigious symbols of authority from the time of the Inka which reinforced their colonial position. In particular, these treasures commemorated their ancestors, who had been captains of the Inkas and had organized the labor force in the cocales, as well as during seasonal agricultural ceremonies and military festivals.

Key words: Andean ethnohistory, coca, curacas, border, Pocona and Totora, pre-Colombian and colonial iconography.

La valorización del uso tradicional de las hojas de coca en los Andes fue una de las inquietudes que acompañó a Murra a lo largo de su vida. Frecuentemente hacía notar la abismal diferencia entre el uso cotidiano de la hoja, íntimamente vinculado a la vida ritual y laboral de los campesinos, y el consumo del producto industrial o cocaína. En este sentido, enfatizaba que el desconocimiento de su sacralidad y de su uso tradicional para obtener un mayor rendimiento físico o un efecto curativo $\mathrm{y}$ en actividades ceremoniales, favorece las subsiguientes propuestas de erradicación. En su tenaz prédica, Murra eligió el camino de la historia para demostrar la importancia vital y el valor de la hoja de coca para el hombre andino. Fue así como hace más de una década y bajo estas preocupaciones publicó la visita de Sonqo (1568-70) en los yungas del norte de La Paz (Murra 1991a). En su estudio comenzó a desentrañar el complejo mundo de la actividad cocalera colonial, subrayando que desde muy temprano se reconoció no solo su importancia económica sino también su valor para la vida social y ritual campesina (Murra 1991b y c).

Siguiendo los lineamientos trazados por Murra, en el presente trabajo propongo analizar otro contexto cocalero de extraordinaria importancia económica y político-ritual ubicado en los valles de Pocona y Totora de la provincia de Charcas en el siglo XVI. Como en el caso de Sonqo, la producción de las hojas de coca (antes para el Inka y luego destinada al mercado potosino), la multietnicidad poblacional y los vínculos fronterizos ambivalentes entre las etnias de los valles mesotérmicos con los grupos del piedemonte amazónico, constituyeron una suerte de hilo conductor que enlazó el mundo prehispánico andino con el colonial, ofreciendo una interesante ventana para comprender los cambios y las continuidades de esta porción fronteriza. Sin duda, los cuarenta primeros años de presencia hispana en el trayecto que unía a Pocona y Mizque, denominado en las crónicas como "Pocona" y en primeros años de la conquista hispana como el "valle de la

1 Department of Anthropology, National Museum of Natural History, Smithsonian Institution, Washington D.C., U.S. mercedes3310@verizon.net 
Canela", abrieron las puertas a la conformación de una cultura andino-colonial regional. Casi sin solución de continuidad, la elite cacical de esta porción del Umasuyu amasó durante la colonia temprana una identidad que hacía referencia al "tiempo del inka", especialmente al prestigioso rol que tuvieron sus antepasados, muchos de ellos miembros destacados de las dinastías regionales locales, en el aparato administrativo del Tawantinsuyu. En otras palabras, en esta región cocalera se rearmó un proceso identificatorio que si bien era marcadamente colonial, simultáneamente aludía a las tareas que desempeñaron los "capitanes del inka" en la frontera del Umasuyu y que permitió a sus descendientes controlar en la colonia los cargos máximos de la sociedad local. El conjunto de imágenes, objetos $\mathrm{y}$ territorios cacicales del temprano siglo XVI que analizaremos a continuación sirvieron sin duda para legitimar sus rangos y jerarquías de autoridad pero también ofrecen un magnífico marco para comprender las permanencias, las transformaciones y las reinterpretaciones del propio pasado andino. Pero previamente efectuaremos un breve análisis del contexto histórico-social de estos yungas charqueños.

\section{EI Paisaje Social de la Frontera: los Mitmaqkuna, los Cocales y la Guerra}

Las fuentes más confiables asignan al Inka Pachakuti o a su heredero y jefe militar Inka Tupaq Yupanki las alianzas con algunos grupos del Collao y de Charcas y la consiguiente organización del Qullasuyu. La versión que recogió Sarmiento de Gamboa sugiere precisamente que los capitanes de Pachakuti, Amaru Tupaq Inka y Apu Paukar Usno, vencieron a los ejércitos charqueños, quienes a su vez en señal de vasallaje les confiaron las importantes minas de Porco (Sarmiento de Gamboa 1943 [1572]:98).

Una vez consolidada la victoria del Cusco sobre estos señoríos, la mayoría de los cronistas concuerdan que Tupaq Inka Yupanki y sus tenientes fueron los encargados de organizar la frontera militar de Pocona y las fortalezas de Pocona, Samaipata, Cuzcotoro e Incahuasi logrando algunas incursiones por el Beni y el Madre de Dios.

La "Memoria de las Provincias" presentada por los miembros del ayllu real Qhapaq Ayllu, descendientes de Tupaq InkaYupanki en 1569, ilumina las hazañas efectuadas por este inka y sus parientes, destacando además que este gobernante había trasladado a la frontera grupos de mitmaqkuna o colonos a cargo de orejones cusqueños:

y salieron [Tupaq Yupanki y posiblemente
sus tenientes] a pocona y hicieron muchas
fortalezas en el mismo pocona y en sabaypata
que es en los chiriguanas y en cuzcotuiro".
"y pusso en todas las fortale[za]s muchos
indios de diversas partes para que guardasen
la dha fortaleza y frontera a donde dexo
muchos yndios orexones y al presente
estan poblados sus hijos y descendientes
en las dhas fortale[za]s y fronteras (Rowe
1985:226).

Pero fue su sucesor, Wayna Qhapaq, quien al regreso de su campaña contra los Chachapoyas, se dirigió al Qullasuyu y con la ayuda de los señores locales reconstruyó las antiguas fortalezas y aquellas que había dispuesto su padre y simultáneamente organizó nuevas excursiones punitivas hacia el piedemonte amazónico. Fundamentalmente, fue quien "puso orden" en la frontera, es decir, profundizó la reforma administrativa y económica regional ${ }^{1}$.

En términos generales, el éxito de la expansión incaica estaba basado en las alianzas políticas con las dinastías regionales. A través de un gobierno mayoritariamente indirecto pudieron contar con la mano de obra movilizada por los señores hereditarios. Por su parte, el Tawantinsuyu proveía protección, infraestructura (caminos, tambos y depósitos) y ciertos privilegios para los linajes integrados al sistema administrativo estatal. Precisamente, los testimonios de los testigos en las probanzas de los Ayawiri (Charka) destacan la colaboración que brindó su antepasado, Kuysara, señor de 10.000 vasallos, a Wayna Qhapaq en las expediciones contra los chiriwana, siendo recompensado, entre otros regalos, con asignaciones o reconfirmaciones de accesos en los cocales de los yungas de Chuquioma en Pocona (Platt et al. 2006:939).

Los inkas habían reestructurado la región cochabambina combinando políticas de reasentamientos masivos locales con otros de larga distancia organizados para la producción de cereales y cocalera. Wayna Qhapaq organizó en esta región dos enclaves económicos estatales de gran importancia: (a) uno en el valle bajo de Cochabamba orientado al cultivo de cereales para el ejército imperial (Wachtel 1981:21-57) y (b) un enclave cocalero 
en los yungas de Pocona y de Totora (Julien 1998; Meruvia Valderrama 2000; Muñoz 2006; Schramm 1990 a y b, 1995)

Desde los valles cochabambinos trasladó algunos grupos Charka (Turpas) y a otros "indios de arco y flecha" como los Quta, Chuy y a sus subalternos llamados Yumos y Raches, que controlaban islotes desde el río Cotacaxa hasta el valle de Cliza, Pojo y Omereque. A todos ellos los relocalizó en la frontera de Pocona, Totora, Mizque y Chunguri. Esta compleja red multiétnica fue enriquecida con el aporte de otros mitmaqkuna provenientes de lugares más distantes y de distinto nivel de complejidad sociopolítica como los Kunti, Chicha, Qulla, Inka, Kanas, Sura, Muyumuyu, Churumata Sura y otros del Chinchaysuyu.

Los ayllus de este complejo entretejido social estuvieron a cargo de mallku (caciques) asentados en los mismos valles, pertenecientes a los linajes Jarajuri [Xaraxuri] y Turumaya. El primero a cargo de grupos heterogéneos y multilingüísticos como los Quta, Qhawi y Chuy, en tanto el segundo, casado con una mujer de estirpe cusqueña, de los restantes mitmaqkuna. Los linajes Jarajuri habían tenido previamente su centro en Sacaba (valle bajo de Cochabamba) y tenían amplia experiencia en la dirección de la producción cocalera en los yungas de Oma y Arepucho, muy cercanos a su centro principal $^{2}$. Es razonable pensar que los inkas privilegiaran a este mallku para comandar a los Quta en las tareas de producción cocalera estatal en los valles de Pocona, confiando en su previa experiencia cochabambina. En 1556, los españoles consideraban a los Quta como los "naturales" u originarios de Pocona, dando a entender que habitaban esta zona antes del arribo incaico. En este sentido, el destierro y la relocalización Quta no fue masiva sino acotada a un grupo de ayllus que vivían en torno al valle cochabambino quienes acompañaron a sus curacas en la colonización de Pocona y sus yungas (Barragán 1994; Schramm 1995, 1990a) ${ }^{3}$. Pero también había en las cercanías de Pocona, precisamente en Totora, otro Kuysara, grupo de mitmaqkuna Charka y Qaraqara controlados por Kuysara, y Muruq'u desde sus cabeceras en las tierras altas y distantes de Charcas, que trabajaban en los cocales del Inka y de sus señores, entremezclándose así los intereses locales con los estatales (Julien 1998; Platt et al. 2006) ${ }^{4}$.

Este archipiélago étnico a cargo de la producción cocalera y de su defensa fue provisto por los cusqueños de buenos islotes complementarios de tierras que les facilitaban su abastecimiento diario de papas, maíz, algodón, maní, ají, pastos para sus ganados y accesos en los cocales para sus curacas. En retribución, los coca kamayuq o especialistas en coca debían recoger, secar y encestar las hojas de coca por turnos laborales (mita) o en forma permanente en las chacras del Inka y de sus señores ubicadas en Chuquioma e Ychamoro y luego llevarlas a los depósitos de Tiraque. Pero también podían ser convocados por turnos para la guerra, cuando las situaciones de conflicto lo ameritaban. Recordemos que los Chuy, Chicha, Charka y Qaraqara fueron "los soldados del inka" y debían estar alistados también para estas tareas.

A los pocos años de instalados en los nuevos territorios o de haber sido reconfirmados en los antiguos accesos, los diferentes grupos pudieron amojonar y deslindar las tierras interétnicas, separarlas de las estatales y las del culto. Pero también pudieron organizar los cultos locales y estatales, confirmar sus wak'a y adoratorios adonde efectuaban sus sacrificios y peregrinajes, tal como lo pudo observar en los años sesenta el Lic. Polo de Ondegardo. En efecto, cuando estuvo en Pocona con el objeto de recoger la opinión de los indios sobre el tema de la perpetuidad de las encomiendas, tuvo la oportunidad de mostrarle al Obispo Fray Domingo de Santo Tomás una carta con las wak'a, ceques y adoratorios que le pintaron los descendientes de los linajes Jarajuri y Turumaya de Pocona, semejante a la carta de ceques del Cusco ${ }^{5}$.

En resumidas cuentas, los señores de las dinastías locales junto a los miembros de la nobleza y de la burocracia cusqueña tuvieron a cargo un importante complejo religioso-militar y económico fronterizo en el eje Pocona-Totora-Mizque. De un lado, organizaron el extendido archipiélago multiétnico de islotes territoriales complementarios, ordenaron su fuerza laboral que, por turnos, debían acudir a los cocales estatales y de sus señores como así también las actividades ceremoniales y rituales vinculadas con el ciclo agrícola. Simultáneamente, estos mallku incorporados algunos de ellos en la jerarquía administrativa del estado con rangos elevados o títulos honoríficos como el de "capitán" o el de "inka" participaban en la defensa de la frontera cocalera y maicera de las incursiones de los grupos del piedemonte amazónico mitmaqkuna. Precisamente, un testigo en la probanza de los Ayawiri comentaba que las fortalezas de la frontera charqueña estaban 


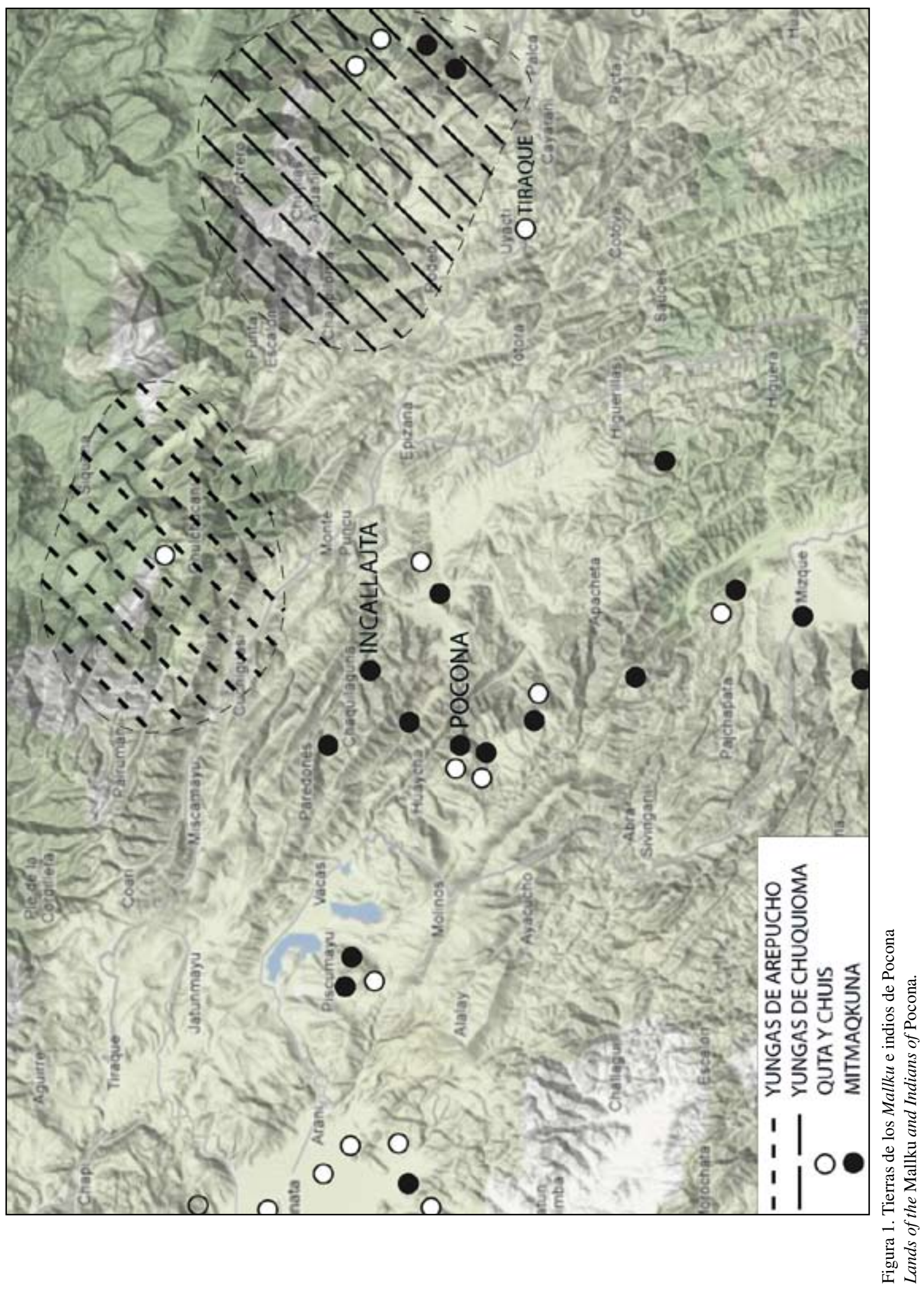


a cargo de un gobernador que, al igual que los señores de Paria y de Charka, gozaba del privilegio de ser llevado en andas y además ostentaba el título honorífico de "Inka"6.

Es importante destacar que no había un estado permanente de beligerancia con los grupos amazónicos sino hitos cíclicos de violencia, sobre todo con los grupos de filiación guaraní, que alternaban con períodos de estabilidad. En los momentos de crisis, los capitanes (generalmente, señores locales ascendidos a "inkas de privilegio") y las altas jerarquías cusqueñas convocaban en los tambos o en las fortalezas a los campesinos ${ }^{7}$. Sin embargo, la frontera incaica no fue simplemente una impenetrable línea militar jalonada por fortalezas, sino un borde bastante más amplio y complejo, de límites difusos y políticamente inestables (Alconini 2002; Pärssinen y Korpisaari 2003; Renard-Casevitz et al. 1988; Saignes 1985; Schramm 1990a, 1995). El borde más cercano al corazón territorial de los señoríos regionales incluía una serie de sitios defensivos, entretejidos por una red de asentamientos agrícolas multiétnicos, caminos y sitios de almacenamiento. Tal es el caso de Incallajta, la fortaleza más cercana a Pocona ubicada en el valle del río Machacamarca (Figura 1$)^{8}$. Un poco más allá de la línea defensiva y en dirección de las tierras bajas se hallaban los cocales y una serie de sitios defensivos menores que a su vez protegían las islas productivas de los avances y hostigamientos más hostiles, pero también eran centros de valiosos intercambios, arreglos políticos con los grupos más dóciles de la región chaqueña y puntos de partida para las entradas incaicas más audaces y esporádicas hacia la frontera con Brasil (Siiriäinen y Pärssinen 1997). Estos argumentos nos permitirían plantear que los edificios denominados "fortalezas" en las fuentes no solo fueron sitios simplemente defensivos donde pernoctaban los guerreros, celebraban las victorias o ceremonias guerreras (danzas, tinkus, etc.) sino que también, en los momentos de mayor estabilidad, los "capitanes del inka" y los funcionarios estatales pudieron congregar a la población campesina para conmemorar las ceremonias íntimamente vinculadas con el calendario agrícola-festivo en torno al cultivo de las hojas de coca.

\section{La Conquista de Charcas y la Frontera}

Las versiones recogidas por Cieza de León, Betanzos y Murúa nos ofrecen un relato vívido del arribo de los ejércitos hispanos a Charcas, pero también dejan entrever los vínculos de los valles de Pocona y de sus dirigentes con el Cusco (Betanzos 1987 [1551]: cap. 34; Cieza de León 1991:380-386; Murúa 2004 [1615]:251-254).

Uno de los personajes más importantes de estas narraciones fue Tisuq, un antiguo general que, a instancias de su hermano Manqu Inka, ejecutó en Pocona al Apu Challku Yupanqui, gobernador del Qullasuyu, por haber colaborado con Almagro en su entrada a Chile (Santos Escobar 1987). Conforme a algunos relatos, cuando las tropas españolas acompañadas por las de Pawllu bajaron desde el altiplano de Paria, tuvieron un primer encuentro en Tapacarí con los Charka, Surasura y Chuy, al mando del Tisuq. Esta primera derrota facilitó el acceso de los españoles al valle de Cochabamba y la retirada de los indígenas. Según cuenta Cieza de León, un grupo pequeño de españoles acaudillados por Gonzalo Pizarro y con la vital presencia de Pawllu se enfrentó a un grueso número de guerreros charqueños. Comandados por un señor principal llamado Torinaseo (Titurinaseo?), Kuysara, los señores Chicha y de Pocona, entre otros capitanes y caciques, cercaron a los invasores en Cochabamba ${ }^{9}$. Los acompañaban sus sacerdotes y las representaciones en oro, plata y madera de sus deidades locales y estatales a quienes invocaban antes de la batalla, hacían sacrificios y celebraciones con abundancia de comida y chicha ${ }^{10}$. Como solía ocurrir en otras ocasiones, los ritos guerreros propiciatorios señalados por Cieza de León tenían por objetivo debilitar el poder de las wak'a de los enemigos porque ellas constituían el fundamento del grupo y su destrucción era el medio para obtener el triunfo final y la captura del botín.

Gonzalo Pizarro dividió su ejército en tres partes y después de contraatacar toda la noche alcanzaron la victoria. Simultáneamente, los refuerzos que Tisuq estaba organizando en el valle de Pocona fueron inmediatamente desbaratados por el capitán Garcilaso de la Vega. Según Murúa, Tisuq y sus aliados debieron huir hacia territorio Chicha y luego a la quebrada de Humahuaca. Desde Pocona, Pawllu logró atraerlos prometiéndoles el perdón y desde allí, junto a otros prisioneros del Collao, regresaron al Cusco. Kuysara finalmente se rindió en el tambo de Auquimarca, luego siguió Tarique (Taraque, Turiquipa o Tiraque?), el señor de los Muyumuyu y el de los Chicha. La nueva alianza con los invasores hispanos se había sellado con la entrega de las famosas minas de Porco y el apoyo a la instalación en Chuquisaca. 
Según Toribio de Alcaraz, testigo en la probanza de los Ayawiri de 1583, sostenía que los principales caciques aliados de los españoles, después de una corta resistencia, como Kuysara (Charka), Moroco (Qaraqara), Jarajuri (Pocona), Turiquipa y Turumaya huyeron por temor a las represalias de Manqu Inka. No sabemos exactamente los lazos de parentesco de los Jarajuri y los Turumaya coloniales con los homónimos de estas memorias, pero sin duda constituyeron apellidos paradigmáticos que se multiplicaron sucesivamente en estos yungas coloniales y que rememoran sucesos fundacionales.

\section{Las Encomiendas Cocaleras de Pocona y Totora y los Territorios Étnicos}

A los pocos años de la invasión hispana, la población de Pocona y de Totora quedó repartida arbitrariamente entre distintos encomenderos cuyas jurisdicciones se fueron reacomodando sucesivamente ${ }^{11}$. Acostumbrados a tributar servicios y parte de su tiempo conforme a las negociaciones alcanzadas entre el Cusco y los señores locales, debieron en forma compulsiva y a veces negociada encauzar la tributación hacia productos. El sistema laboral siguió, como en tiempos prehispánicos, orientado a la recolección de hojas de coca por turnos en "las chacras que eran del inka" y a su transporte y almacenamiento en los depósitos de Tiraque y Totora, aunque esta vez los encomenderos recogían la producción cocalera para proveer a los mercados altiplánicos. Junto con la encomienda de Pedro de Hinojosa, Pocona fue una de las más rentables de Charcas. En cuanto a Totora, el tema es bastante más complejo porque los pequeños grupos de mitmaqkuna (fundamentalmente Charka, especializados en el cultivo de coca, y Churumata) dependían de encomenderos que habían obtenido jurisdicciones mayores con cabeceras en otros lugares. En algunos casos, sus indios aún mantenían los accesos prehispánicos a los cocales y en otros les adscribieron pequeños grupos de mitmaqkuna. En Totora había al menos unos 600 mitmaqkuna charqueños, que habían estado sujetos a Kuysara, y recogían más de 2.000 cestos de coca de las chacras "que diz que eran del inka"12. Un poco más al sur, los valles de Mizque también fueron multiétnicos poblados por Chuy y grupos del Antisuyu. Pero las bajas demográficas en Pocona, Mizque y Totora fueron tremendamente importantes y con el paso del tiempo los Charka fueron perdiendo poco a poco sus lazos con las cabeceras y muchos cocales fueron vendidos a los españoles. Esta crisis demográfica estuvo motivada por múltiples factores: las guerras de conquista, el excesivo trabajo en los cocales, el regreso de los colonos a sus cabeceras de origen en forma voluntaria o recogidos por sus propios curacas o por pasar como yanakuna al servicio de españoles. Pero además, la frontera seguía siendo una zona muy inestable. A las recurrentes hostilidades de los chiriwana, se habían sumado ahora las de los Yurakarés quienes atacaban la ruta a Santa Cruz y a los cocales. No obstante, las relaciones eran muy complejas y ambiguas ya que algunos de los grupos de los valles interiores como los Chuy tenían vínculos políticos y de parentesco con muchos de los que realizaban frecuentes intercambios.

Gracias a la visita efectuada por Melchor de Horozco el 16 de mayo de 1556 contamos con una temprana información sobre las autoridades étnicas, territorios y población de la encomienda de Pocona. Habían transcurrido tan solo 17 años de la rendición de los señores charqueños y de los mitmaqkuna de Pocona al ejército de los hermanos Pizarro y algunos linajes aún vinculados a los líderes prehispánicos mantenían el control político de unas 2.600 personas (679 tributarios), a pesar de haber sufrido una fuerte declinación. Las principales autoridades hereditarias de Pocona eran don Juan Jarajuri y don Hernando Turumayo (Medinacelli y Mendieta 1997; Ramírez Valverde 1970 [1557]:269-309) $)^{13}$.

Don Juan Jarajuri como sucesor de su padre don Diego Jarajuri fue "gobernador de Pocona de los Quta Qullasuyu” por unos 25 años hasta su muerte acaecida en 1580. Le acompañaba don Pedro Chirima como cacique de los Quta de Urinsaya y sucesor de su padre Laca, un cacique no bautizado del "tiempo del ynga"14. También había otra parcialidad a cargo de Don Felipe, sujeto y con una jerarquía inferior a Jarajuri. Cada uno de estos caciques tenía a su vez uno o dos principales a cargo, generalmente de su parentela.

En cuanto a don Hernando Turumayo, fue el cacique principal de los mitmaqkuna de Pocona y gobernaba a un grupo de curacas de menor jerarquía a cargo de los Kunti, Inka, Chinchaysuyu y Qullasuyu ${ }^{15}$. También había otras agrupaciones de mitmaqkuna, una a cargo de don Tomás Caua, cacique de los Qulla de Chimboata, y otra de Sura, al mando de don Pedro Cayo, quienes gozaban aparentemente de cierta independencia. Fray Francisco 
Rincón comentaba en esa visita que los mitmaqkuna tenían diversos caciques, "cada uno quiere mandar e como no tengan una cabeza que los rijan andan muy desconcertados" sugiriendo como autoridad a don Hernando Turumaya porque "entiende en cosas de españoles". La gran mayoría de los pobladores vivían dispersos en los valles de Chimboata, Punata, Copi, Conda, Aramasi cultivando maíz, trigo, algodón, ají, maní y la hoja de coca en los enclaves de los yungas de Chuquioma, Ychamoro y Arepucho. Tres veces al año bajaban a los yungas, por turnos o mitas para secar y encestar la coca y depositarla en el asiento de Tiraque, tal como lo habían hecho en décadas anteriores para el inka ${ }^{16}$.

Don Juan Jarajuri gobernaba un grupo relativamente pequeño de hombres adultos que, mayoritariamente, residían en chacras cercanas al asiento de Pocona ${ }^{17}$ y los restantes en diversas islas territoriales. Por su lado, los mitmaqkuna de Turumaya constituían el grupo más numeroso de la encomienda y estaban concentrados en Pocona, Copi, o en las antiguas tierras estatales de Conda ${ }^{18}$ (Tabla 1). Al igual que en Sonqo, los hogares cacicales eran poligínicos, tenían yanakuna, kamayuq y mujeres de servicio, numerosos hijos, hermanos y disponían de varias casas dispersas en distintos ambientes ecológicos (Murra 1991c:654). Los caciques de mayor rango reunían en sus "casas" una parentela de unas 40 personas, mientras que los de menor rango alcanzaban la docena. A excepción del Qulla don Tomas Caua, cacique del pueblo de Chimboata, los restantes tenían residencia en el asiento de Pocona. Sin embargo, Jarajuri también conservaba otra casa en Sacaba (Cochabamba) y sus cocales en Oma. Después de 20 años de vida colonial y efectuadas las reformas toledanas, los caciques aumentaron el número de propiedades, casas y solares en la plaza de Pocona e inclusive el hijo del Qulla Caua se trasladó de Chimboata a una casa con tejas y huerto en las afueras de Pocona, además de otras en Copi, Chuquisaca, Chuquioma y depósitos en Tiraque ${ }^{19}$ (Tabla 2).

En cuanto a las tierras cacicales, los tres caciques de los Quta tenían sus accesos en Chimboata, Conda, Siaco y Chusamarca. Jarajuri también tenía una viña en Julpe, tierras en Layminia y en el pucará de Machacamarca, en Tuironi y maíz en Chunguri, unas 2.000 yeguas, 200 vacas y 160 ovejas. En cambio, Turumaya los tenía en Tocori y Cinse.
Mientras que don Tomás Caua y más tarde su hijo don Pedro Arapa, concentraban sus parcelas en Chimboata, Copoata, Cupi (donde también había Kana, Sura y Kunti, Sura), Chunguri y Ucumari. Sumaba además unas 2.000 ovejas, yeguas, puercos y guacamayos. Finalmente, todos tenían sus coca kamayoq trabajando en sus accesos en los Yungas de Chuquioma, Arepucho y Yurakarés cerca de las chacras de los Charcas de Sakaka y de Chayanta, de los Caracaras y de los Chuis de Mizque, formalmente desvinculados de sus cabeceras ${ }^{20}$.

Los caciques tuvieron muy buenos vínculos de intercambio con mercaderes de La Plata, también vendían carneros a los españoles en los yungas e inclusive Jarajuri llegó a tener lazos de intercambio con don Carlos Inka, a quien le había vendido en los años 60 unas 100 cargas de maíz ${ }^{21}$. Don Carlos Inka tenía algunos indios Kanas de su encomienda residiendo en el pueblo de Copi y ellos se quedaron a cargo de la deuda. Evidentemente, los mitmaqkuna Kanas de Pocona no habían cortado los lazos con sus parientes ubicados en los territorios de origen como así tampoco los Kunti quienes aún estaban vinculados a su curaca Alonso Molo Arcaya de Arequipa $^{22}$.

En cuanto a Totora, los antiguos mitmaqkuna Charka y Churumatas que habían sido también colonos puestos allí para el beneficio de las tierras del inka, gradualmente fueron perdiendo los vínculos con sus cabeceras, aunque todavía pudieron mantener sus redes sociales. Hacia los años ochenta del siglo XVI, el cacique principal de Totora, don Pedro Xauxa, aún conservaba los pastos y ganados en Sakaka “...pueblo de donde era natural mi padre...", pero por otro lado accedió a unas 4 chacras en los yungas (Sapsi, Chuquioma y Apacheta) y a tierras de maíz y de papas (Tontori) que habían sido de Kuysara $^{23}$. La modesta producción de coca de sus chacras servía para reforzar vínculos sociales no solo con los Turpa sino también con Sura, mestizos o españoles. Así por ejemplo, intercambiaba cestos por servicios laborales, o por una espada o prestaba coca para que pagaran la tasa. También llevaba cestos a Chuquisaca o Mizque en sus carneros. Desconocemos cómo estaba conformada la red de autoridades de Totora, tan solo sabemos que a su muerte le sucedió su yerno el alcalde de Pocona, don Diego Turumaya, por cierto de un nombre muy significativo en la historia regional. 
Tabla 1. Tierras cacicales

Land of the Caciques.

\begin{tabular}{|c|c|c|c|c|c|}
\hline Ubicación & Nombre & $\begin{array}{l}\text { Pedro Chirima } \\
\text { (?-1584), Cacique } \\
\text { (urin), Quta }\end{array}$ & $\begin{array}{c}\text { Juan Xaraxuri, (?-1580), } \\
\text { Gobernador, } \\
\text { Quta }\end{array}$ & $\begin{array}{c}\text { Pedro Arapa, } \\
\text { (?-1574), Cacique Principal, } \\
\text { Qulla }\end{array}$ & $\begin{array}{l}\text { Pedro Xauxa, } \\
\text { (?-1583), Cacique } \\
\text { principal, Charka }\end{array}$ \\
\hline Valle Pocona & $\begin{array}{l}\text { Sacapampa } \\
\text { Aremisa } \\
\text { Cuchiyapo } \\
\text { Otayre } \\
\text { Calacala } \\
\text { Machaca-marca } \\
\end{array}$ & $\begin{array}{l}1 \text { chacra de maíz } \\
1 \text { chacra de maíz } \\
1 \text { chacra de maíz } \\
1 \text { chacra de maíz } \\
1 \text { chacra de maíz }\end{array}$ & $\begin{array}{l}1 \text { chacra } \\
1 \text { ch. (Challajapo) } \\
1 \text { ch. en el pucara y pastos }\end{array}$ & 1 chacra de maíz & \\
\hline Chimboata & $\begin{array}{l}\text { S/i } \\
\text { Llallagua } \\
\text { Crusa } \\
\text { Hachapampa } \\
\text { Pampa } \\
\text { Utahca } \\
\text { Pilancho }\end{array}$ & $\begin{array}{l}1 \text { chacra de maíz } \\
1 \text { chacra de maíz } \\
1 \text { chacra de maíz } \\
1 \text { chacra de maíz }\end{array}$ & 3 ch, de maíz y pastos & $\begin{array}{l}1 \text { ch. de su padre } 500 \text { maíz } 100 \text { c papas. } \\
\text { huerta }\end{array}$ & \\
\hline Conda & $\begin{array}{l}\text { S/i } \\
\text { Hayahaya } \\
\text { Trigopampa } \\
\text { Cocho } \\
\text { Yucaya } \\
\text { Cocatayapo? }\end{array}$ & $\begin{array}{l}1 \text { chacra de maíz } \\
1 \text { chacra de maíz } \\
1 \text { chacra de maíz } \\
1 \text { chacra de maíz } \\
1 \text { chacra de maíz }\end{array}$ & 2 chacras & & \\
\hline Copi $^{1}$ & & & & 4 ch./150 c maíz & \\
\hline Copoata & $\begin{array}{l}\text { S/I } \\
\text { Mojon Alpa } \\
\text { Popo } \\
\text { Ero }\end{array}$ & $\begin{array}{l}1 \text { chacra de su padre } \\
1 \text { chacra } \\
1 \text { chacra } \\
\text { Pescadero }\end{array}$ & $\begin{array}{l}1 \text { chacra } \\
3 \text { pedazos y el arroyo }\end{array}$ & 200 c maíz y ch del padre & \\
\hline Sacaba & & & 1 chacra & & \\
\hline Chunguri & & & 1 ch. maíz & $1 \mathrm{ch} / 50 \mathrm{c}$ maíz & \\
\hline Tuyrone & & & 1 chacra de maíz & & \\
\hline Totora & & & & & maíz y papas \\
\hline Valle de Mizque & $\begin{array}{l}\text { S/I } \\
\text { Tucuma }\end{array}$ & & & & \\
\hline Sacaca & & & & & Pastos \\
\hline Tontori & & & & & maíz y papas \\
\hline Xulpe & $\begin{array}{l}\text { Titicaca } \\
\text { Chusmarca } \\
\text { S/I } \\
\end{array}$ & $\begin{array}{l}1 \text { chacra } \\
1 \text { ch. ají y algodón }\end{array}$ & 1 viña & & \\
\hline Luyes & & & & 4 ch/50 c. c/u de algodón, mani y ají & \\
\hline Yungas de Chuquioma & $\begin{array}{l}\text { en el pueblo } \\
\text { S/I } \\
\text { Apacheta } \\
\text { Cocata } \\
\text { Sapsi }^{2} \\
\text { Guayruru } \\
\text { Hotoy (Hutuhavi) } \\
\text { Sunyapo } \\
\text { Milla oma } \\
\end{array}$ & $\begin{array}{l}1 \text { chacra de coca } \\
1 \text { chacra de coca } \\
1 \text { chacra de coca } \\
1 \text { chacra de coca }\end{array}$ & $\begin{array}{l}1 \text { ch. coca } \\
1 \text { ch. coca }\end{array}$ & $\begin{array}{l}1 \text { ch. coca; } 50 \text { c } \\
3 \text { ch; } 50 \text { c } 2 \text { casas } \\
1 \text { ch. } / 50 \text { c }\end{array}$ & $\begin{array}{l}1 \text { pedazo } \\
1 \text { chacra } \\
6 \text { ch. coca, } 10 \mathrm{c} \text {. }\end{array}$ \\
\hline Yungas de Arepucho & $\begin{array}{l}\text { Cotani } \\
\text { Calacala } \\
\text { Cata } \\
\text { Chinima } \\
\text { Siquimira } \\
\text { Cano Oma } \\
\text { Ayna } \\
\end{array}$ & $\begin{array}{l}\text { coca } \\
\text { coca } \\
\text { coca } \\
\text { coca } \\
\text { coca }\end{array}$ & $\begin{array}{l}1 \text { ch. } / 6 \text { c. coca } \\
3 \text { ch. } / 25 \text { c. de coca }\end{array}$ & & \\
\hline Yuracares & Yuracares & $\mathrm{S} / \mathrm{I}$ & 6 c. coca & & \\
\hline Oma & & & $5 \mathrm{ch} . / 43 \mathrm{c}$ de coca & & \\
\hline
\end{tabular}

Fuente: Visita de 1556 y Testamento de don Juan Xaraxuri (1580); Testamento de don Pedro Xauxa (1583); Testamento de don Pedro Chirima (1584), Testamento de don Pedro Arapa (1574).

1 En el pueblo de Cupi hay indios Kanas de don Carlos Inka. También hay Soras y Condes;

2 En Sapse hay tierras de los Chuy. 
Tabla 2. Casas de los mallku.

Houses of the Mallku.

\begin{tabular}{|c|c|c|c|c|}
\hline \multirow[b]{2}{*}{$\begin{array}{l}\text { Ubicación } \\
\text { de las casas }\end{array}$} & \multicolumn{3}{|c|}{ Pocona } & \multirow{2}{*}{$\begin{array}{c}\text { Totora } \\
\text { Pedro Xauxa, } \\
(?-1583), \\
\text { Cacique principal, Charka }\end{array}$} \\
\hline & $\begin{array}{c}\text { Pedro Chirima } \\
\text { (? - 1584), } \\
\text { Cacique (urin), Quta }\end{array}$ & $\begin{array}{c}\text { Juan Xaraxuri, } \\
(?-1580), \\
\text { Gobernador, Quta }\end{array}$ & $\begin{array}{c}\text { Pedro Arapa, } \\
(?-1574), \\
\text { Cacique Principal, Qulla }\end{array}$ & \\
\hline Pueblo Pocona & 1 casa & 1 casa en 1 cuadra & 9 casas y 2 solares (1) & \\
\hline Chimboata & & & 1 casa & \\
\hline Tiraque & & & 1 depósito & \\
\hline Pueblo Copi & & & 1 casa nueva & \\
\hline Sacaba & & 1 casa & & \\
\hline Chuquisaca & & & 1 casa y 4 galpones & \\
\hline Copoata & & 1 casa & & \\
\hline Chuquioma & & & 2 casas y huerto & \\
\hline Totora & & & & casas \\
\hline
\end{tabular}

Fuente: Visita de 1556 y Testamentos.

$1 \quad 1$ casa en el pueblo y 8 en las afueras, una con tejas y huerto.

\section{Los Caciques Coloniales de Pocona y Totora: Una Aproximación a su Patrimonio}

\begin{abstract}
Había en el palacio del Inga así mesmo, de donde se sacaban muchas riquezas, [una]... cámara del tesoro, que ellos llamaban Capacmarca o así como si dijera aposento o sobrado rico del tesoro el cual servía de lo que acá la recámara, guarda ropa y Tesoro del Inga guarda joyas porque en ella están todos los ricos vestidos del Inga (Murúa 2004 [1615]:135).
\end{abstract}

Los treinta primeros años de presencia hispana en esta región fronteriza, habían abierto el camino hacia la conformación de una cultura andino-colonial. La posesión de objetos suntuarios "del tiempo del inka" o el gusto por una "estética incaica" por parte de las elites provinciales permitían legitimar los cacicazgos o manipular jerarquías de autoridad. Estos objetos aludían a la riqueza, al poder y al prestigio de aquellos que los poseían y también a la vida ritual.

Cummins ha señalado que desde la colonia temprana y a lo largo de los Andes se universalizaron entre los mallku los símbolos considerados como incaicos y ellos fueron reconocidos tanto por indios como por españoles. En otras palabras, se generalizó el uso de ciertos objetos, adornos o textiles que antes estaban restringidos para ciertos funcionarios de la jerarquía estatal (Cummins 1998:91-148).
Los mallku de Pocona don Pedro Chirima y don Juan Jarajuri de los Quta, el Qulla don Pedro Arapa (de Azángaro?) y el cacique de los Charka de Totora don Pedro Xauxa tenían un significativo ajuar. Es razonable pensar que parte de ese patrimonio, cargado de mensajes y fuerte simbolismo, aludía a la gloria de sus antepasados y linajes vinculados a la administración incaica, pero en este contexto sirvieron para legitimar frente a sus súbditos y al estado colonial sus jerarquías de autoridad.

No es nuestra intención ni estamos en condiciones de identificar en detalle, en cada uno de los cuatro inventarios, cuáles fueron los bienes heredados de los obtenidos a lo largo de su vida y en este último caso si lo hicieron a través de intercambios, de regalos o en las almonedas locales. Sabemos que, por ejemplo, don Pedro Arapa tenía pillos karanqa (corona o cordón en la cabeza), lienzos y ropa de Santa Cruz e inclusive una hamaca del Paraguay. Pero también tenía unos 10 vestidos cumbi heredados de su padre, aunque sin identificar sus diseños. Los restantes no especificaron los bienes suntuarios que heredaron de sus antepasados. Sin embargo, todos ellos seguían valorando los bienes tradicionales como sus "tesoros". Así por ejemplo, don Pedro Chirima solicitaba que a su muerte no se vendieran sus bienes en almoneda y testó a favor de sus hijos, nietos, yanakuna y servidores y los más significativos como un pillos de oro y algunos tejidos cumbi fueron para "la honra" de su hijo y sucesor. Don Pedro Xauxa especificó para su 
sucesor tres hachas de cobre (símbolo de autoridad y control político) y aquellos bienes suntuarios que no fueron inventariados terminaron en la almoneda $\mathrm{y}$ en poder de su mujer.

En el ajuar cacical había gran cantidad de bienes tradicionales (plumas, textiles y joyas) y en menor proporción prendas al uso europeo (crucifijos, imágenes religiosas, sillas de montar, espadas, etc.) y ambos conjuntos apuntaban al mismo mensaje: afirmar sus jerarquías de autoridad.

Pero volvamos a los bienes tradicionales. En este conjunto también es muy difícil distinguir cuáles fueron prehispánicos y cuáles hechos en la colonia conforme a técnicas, diseños y materiales tradicionales. $\mathrm{Y}$ en este sentido nos podríamos preguntar en qué medida continuaron o se interrumpieron las tradiciones artesanales locales en textiles y en metales. Nos consta, por ejemplo, que los "plateros de Sipesipe" ${ }^{24}$ seguían llamándose así en los años setenta, y proveían de objetos de oro o plata a los caciques locales o por lo menos a los de Pocona y de Tapacarí. Poco sabemos sobre los tejedores de $c u m b i$, tan solo una vaga referencia de testigos también de Sipesipe que decían haber sido "cumbicamayos del ynga" (Gordillo y del Río $1993)^{25}$. Pero qué diseños tejían, en qué depósitos los guardaban en el pasado y si continuaron con sus prácticas tradicionales durante la colonia, son aspectos que aún se nos escapan. En términos generales, los diseños prehispánicos de circulación restringida se generalizaron en la colonia hacia otros miembros de los linajes provinciales aunque siempre vinculados a la elite cacical hereditaria Pero ¿podemos pensar que hacia los años 70-80 del siglo XVI había una "estética inka" generalizada entre los caciques hereditarios de Pocona y Totora?, ¿había alguna diferencia entre ellos?, ¿estamos en condiciones de ahondar un poco más en estos conceptos y preguntarnos si los objetos "del tiempo del inka" que poseían los curacas coloniales de Pocona y de Totora estaban en realidad asociados metafóricamente a las dinastías locales prehispánicas ascendidas a "inkas de privilegio" del Qullasuyu? Nos interesa analizar algunos objetos de su patrimonio.

Por lo pronto, los caciques de los Quta tenían un mayor predominio de prendas al uso indígena. Eran vestidos cumbi compuestos de camiseta y mantas predominantemente amarillas y coloradas, y en menor proporción vestidos de algodón y mantas hechas con telas europeas (Tabla 3). Asimismo poseían una camiseta llamada colcampata que acompañaban con una manta o "yacolla de cumbi fino que se llama quecho". Según Bertonio (1984 [1612]) el término quecho era un vocablo aymara usado por los Pakasas para designar cierto tipo de mantas que otros grupos llamaban Kili. Eran mantas la mitad colorada y la otra azul con tres listas de varios colores tejida como el espinazo del pescado. En cuanto a las camisetas de diseño colcampata, Murúa especifica que eran ajedrezadas (Figura 2). Asimismo, el mallku de Totora tenía mantas amarillas y pardas y camisetas listadas, bastante difundidas entre los mallku aymaras, pero también una camiseta colcampata.

Un caso diferente y notable se presenta en don Pedro Arapa (Qulla), no solo por la riqueza y abundancia de su ajuar, sino por los detalles de su inventario donde se describen más de 25 vestidos en cumbi o abasca señalados en pares (mantas y camisetas) con sus respectivos colores y diseños, dando a entender que cada uno de esos pares de prendas tenía un uso ceremonial específico ${ }^{26}$ (Tabla 3 ).

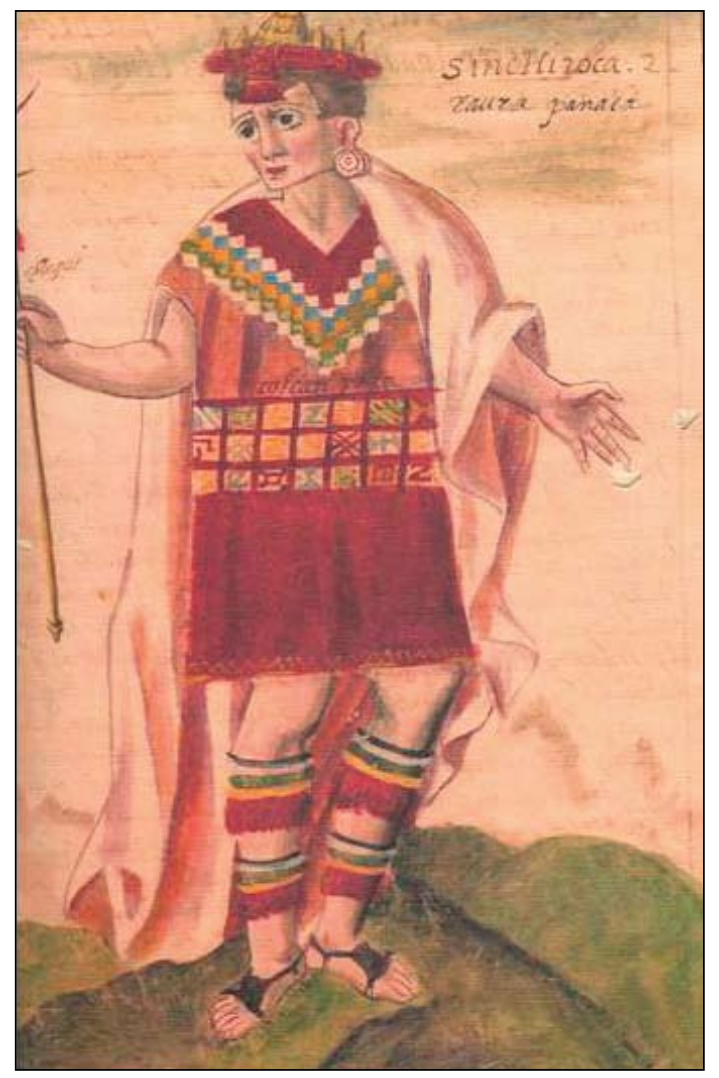

Figura 2. Camiseta colcampata en el Códice Murúa 2004 [1590]:10.

Colcampata tunic in Códice Murúa 2004 [1590]:10. 


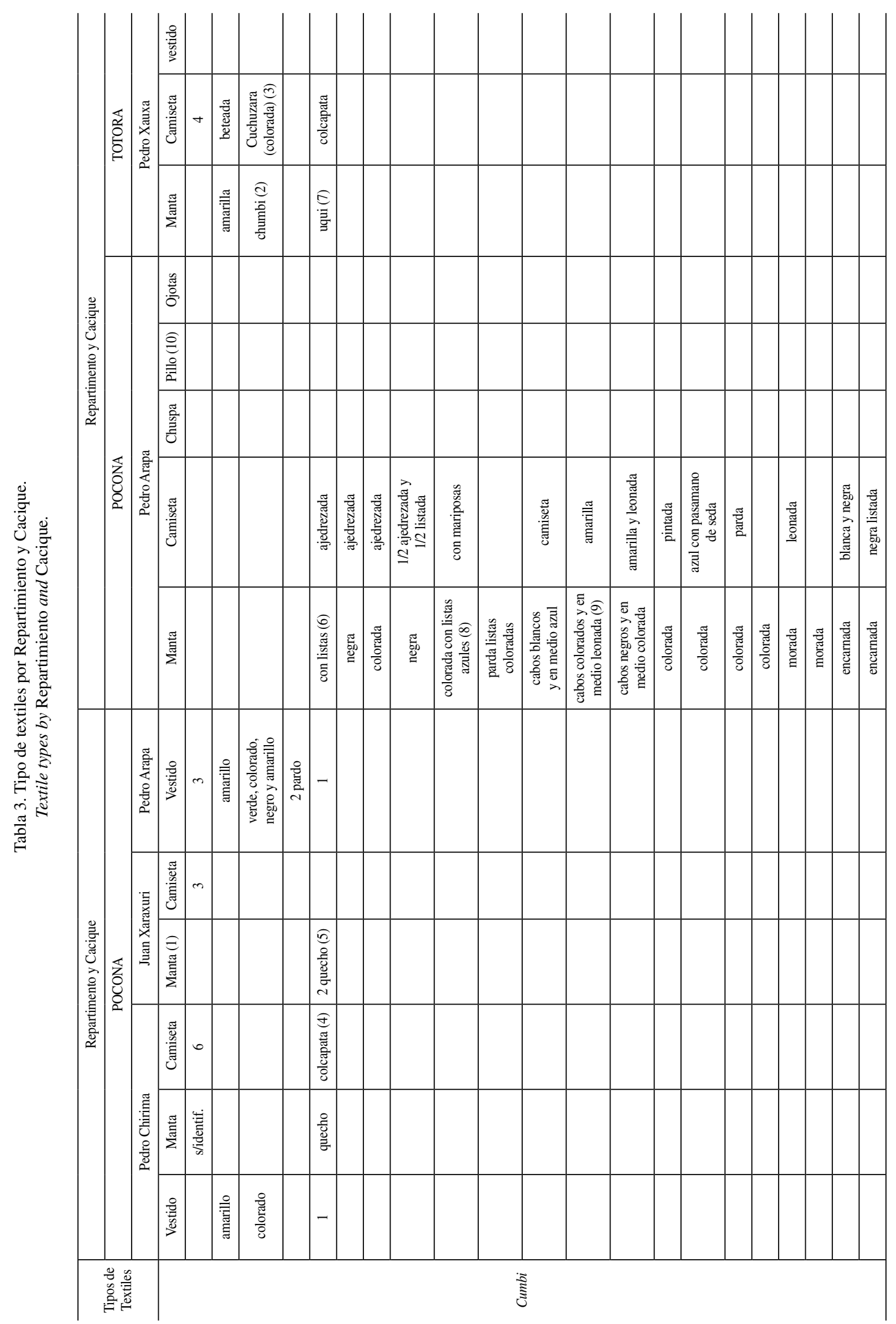




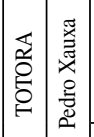

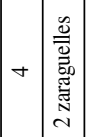

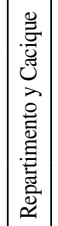

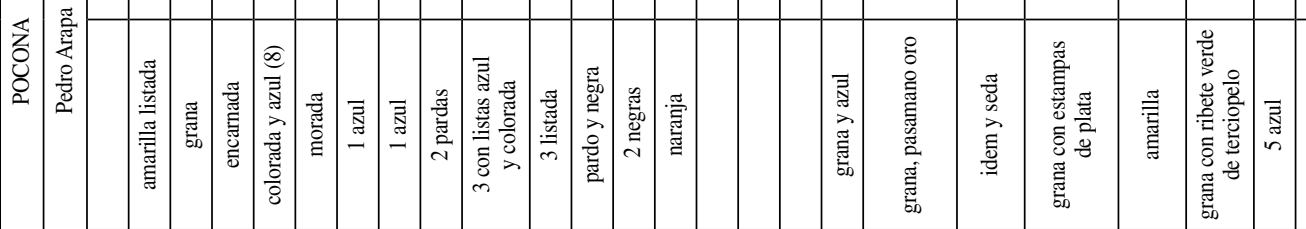

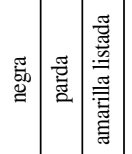

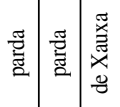

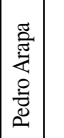

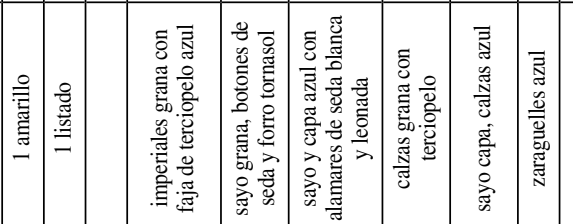

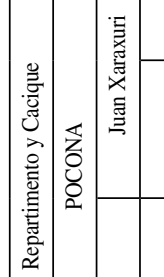

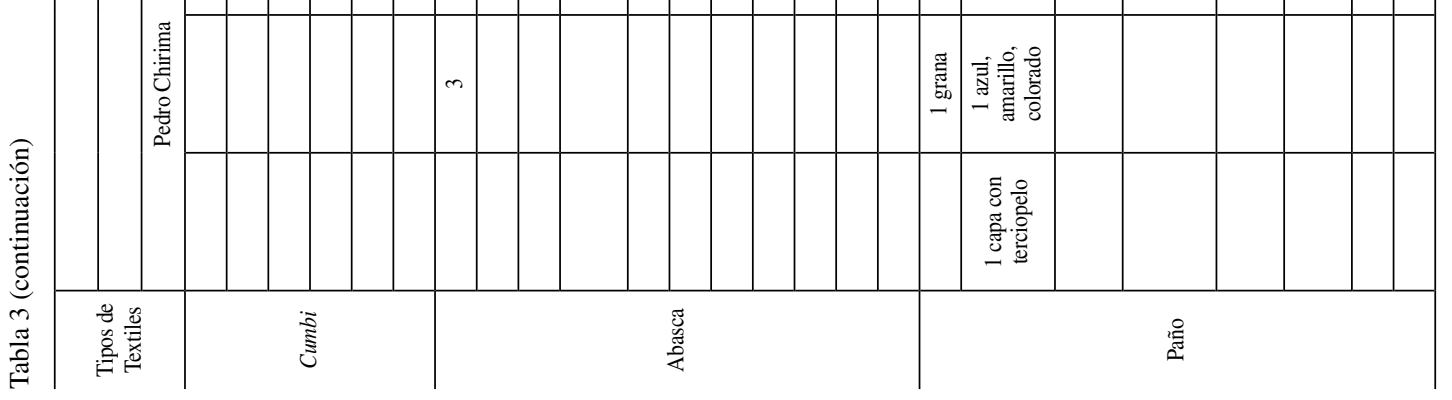




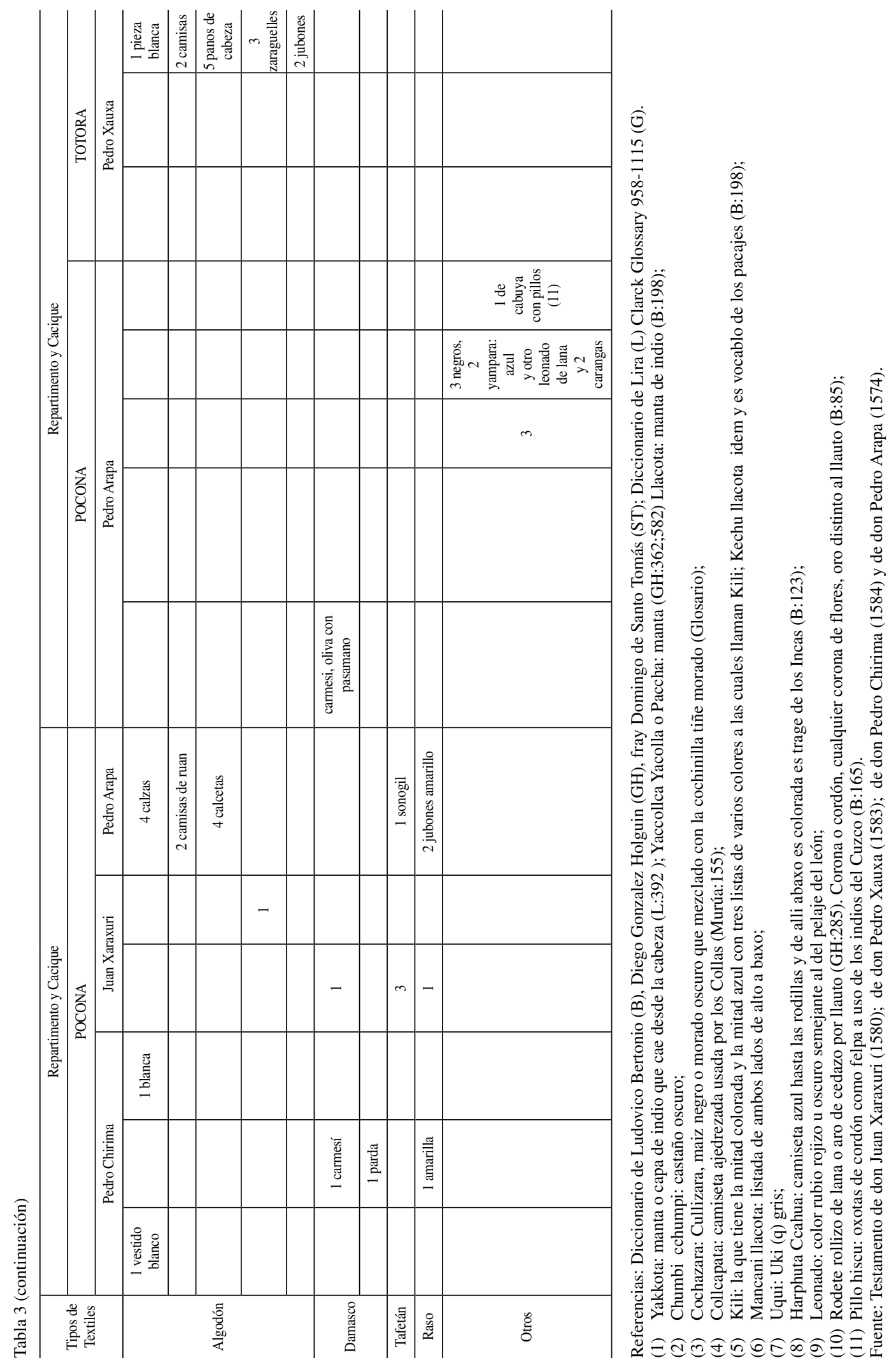


A ello se agregan dos conjuntos al estilo europeo (manta, calza y sayo) y al igual que los vestidos tradicionales los colores predominantes eran el rojo y el azul. Como los otros mallku, Arapa tenía cuatro camisetas ajedrezadas. Una de ellas la combinaba con una manta con listas (quecho?) aclarando que era "ropa del inka". El segundo conjunto estaba compuesto por una camiseta ajedrezada que usaba con una manta negra, el tercero por una camiseta ajedrezada con su manta colorada y el cuarto por una camiseta la mitad ajedrezada y la otra mitad con listas, acompañada por una manta negra (Figura 3). A ello hay que sumar una camiseta con mariposas que llevaba con una manta negra y otra camiseta pintada con manta colorada.

En todos los casos se destacan las camisetas ajedrezadas y decoradas y los colores amarillo, negro, azul y colorado, diseños y colores sobre todo el rojo y azul que aludían al Estado cusqueño, mientras que otras mantas y camisetas listadas eran propiamente aymaras (Gisbert et al. 1992).

Los trabajos de Rowe y Zuidema nos brindan algunas pistas para comprender el significado que al menos tuvieron las prendas ajedrezadas en el período prehispánico (Rowe 1973:239-264; Zuidema 1991:151). Ambos concuerdan que durante el Tawantinsuyu había una cierta estandarización de

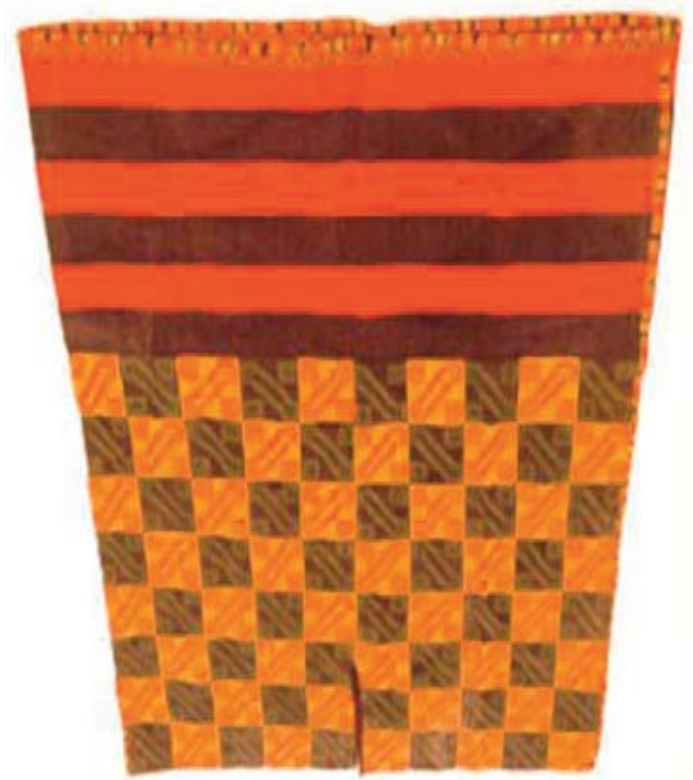

Figura 3. Camiseta (Museo de Arqueología de Alta Montaña, Salta).

Tunic (Museo de Arqueología de Alta Montaña, Salta). los diseños y de las técnicas en las túnicas finas. Rowe propuso cuatro diseños de camisetas estándar que reflejarían las políticas estatales ya que eran tejidas por los cumbikamayoq, guardadas en los depósitos para luego ser redistribuidas por el inka. Nos interesan en este contexto dos: uno llamado damero "blanco y negro" que es una camiseta totalmente ajedrezada con una pequeña proporción lisa en la parte superior y corresponde posiblemente a nuestra colcampata. La otra la llamó "damero del inka" con un diseño en damero en la parte superior y en la inferior listas horizontales que recuerda a la que tenía don Pedro Arapa (Figura 3). Inspirado en estas propuestas, Zuidema retomó los dibujos de Murúa y de Guaman Poma y señaló tres diseños estandarizados, uno de ellos llamado colcampata que indicaba ciertos rangos en la organización política del imperio. Sostiene que son dameros más simples que los usados por los gobernantes incaicos y aludían metafóricamente a las terrazas de cultivos y a las qullqa o depósitos por sus patrones repetitivos y eran usados por los guerreros o durante las ceremonias de la siembra. Pero también Zuidema presta atención a uno de los dibujos de Guaman Poma en el cual la túnica del capitán principal estaba cubierta por mariposas (motivo femenino) usada en el mes de la Coya Raymi cuando se honraba a la luna y a la mujer (septiembre) y durante las ceremonias de la siembra (septiembre) y de la cosecha (mayo) (Figura 4). Además, en septiembre se celebraba la Citua, y en esta celebración se efectuaban los ritos de limpieza para asegurar la fertilidad y crecimiento de los frutos. Los hombres ataviados como si fueran a la guerra, se juntaban en la plaza del Cusco y desde allí salían en diferentes direcciones, conforme a las direcciones de los ceques, para eliminar con sus hondas las enfermedades. Como hemos demostrado el ajuar textil más fino atesorado por los curacas de Pocona tenía claras referencias al tiempo del inka junto a otros textiles propiamente aymaras que usaban, según Guaman Poma, los capitanes del Qullasuyu (Figura 5). Podemos imaginar que sus antepasados, "los capitanes del inka" ataviados con estos "tesoros" celebraban también estas ceremonias agrícolas en las fortalezas cercanas a los cocales estatales. Pero veamos los otros objetos de su patrimonio.

Los objetos de oro y plata también estaban vinculados al tiempo del inka, sobre todo asociados a los mitos de origen de los gobernantes (unión del sol y de la luna), el oro al culto solar mientras que 


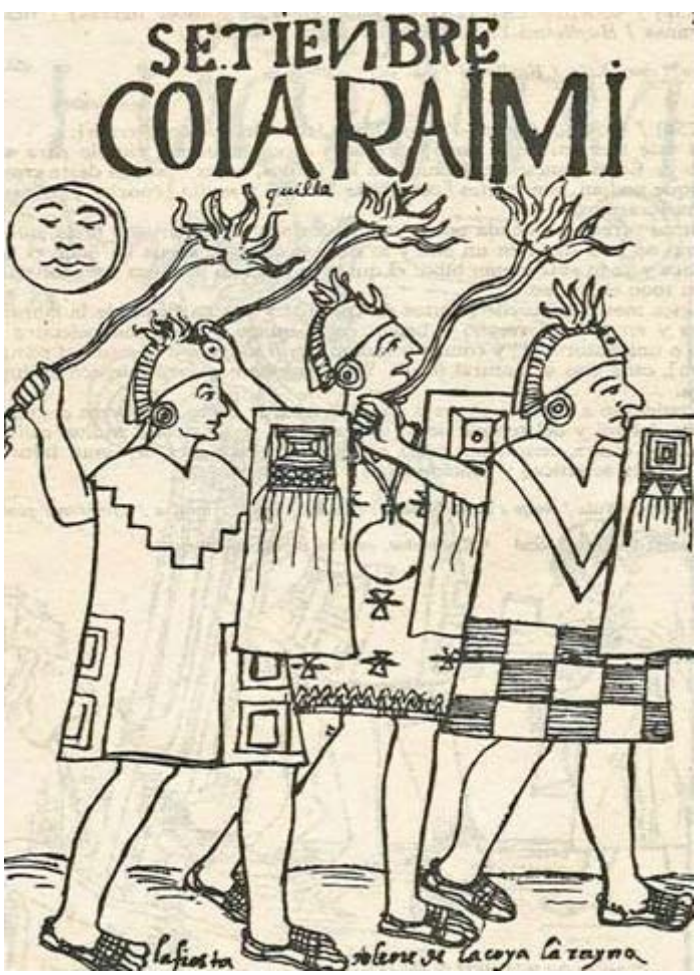

Figura 4. Camiseta con mariposas. Felipe Guaman Poma 1980 [1615/16], editado por J. Murra y R. Adorno, p. 226.

Tunic with butterflies Felipe Guaman Poma 1980 [1615/16], edited by J. Murra and R. Adorno, p. 226.

la plata con la luna y podían sugerir asociaciones de género (oro/masculino; mujeres/femenino) (Lechtman 1975). Como los textiles en cumbi, su uso estaba restringido a las jerarquías cusqueñas y circulaban como regalos entre jefes y guerreros reflejando privilegios y rangos de autoridad.

En los inventarios de los caciques se describe cantidad de objetos en oro y plata y el adorno más difundido fueron las chipanas o brazaletes, aunque tambien tenían orejeras, anillos, macanas con filos de plata, torzales de plata para las hachas y trompetas del mismo metal (derechas o con vueltas) de uso ceremonial (Tabla 4) ${ }^{27}$. El cacique Quta de anansaya usaba en su frente pillos o coronas de oro mientras que el de urinsaya los usaba de plata. En cambio, el caciques Qulla colgaba unas puntas de plata en sus pillos (pinxes) o de oro en su sombrero (chokcho). Es interesante destacar que los Quta usaban unas medias lunas de oro o plata (paure, pariri) con un complemento del mismo metal en la barbilla. En los dibujos de Guaman Poma las medias lunas aparecen adosadas a los pillos o

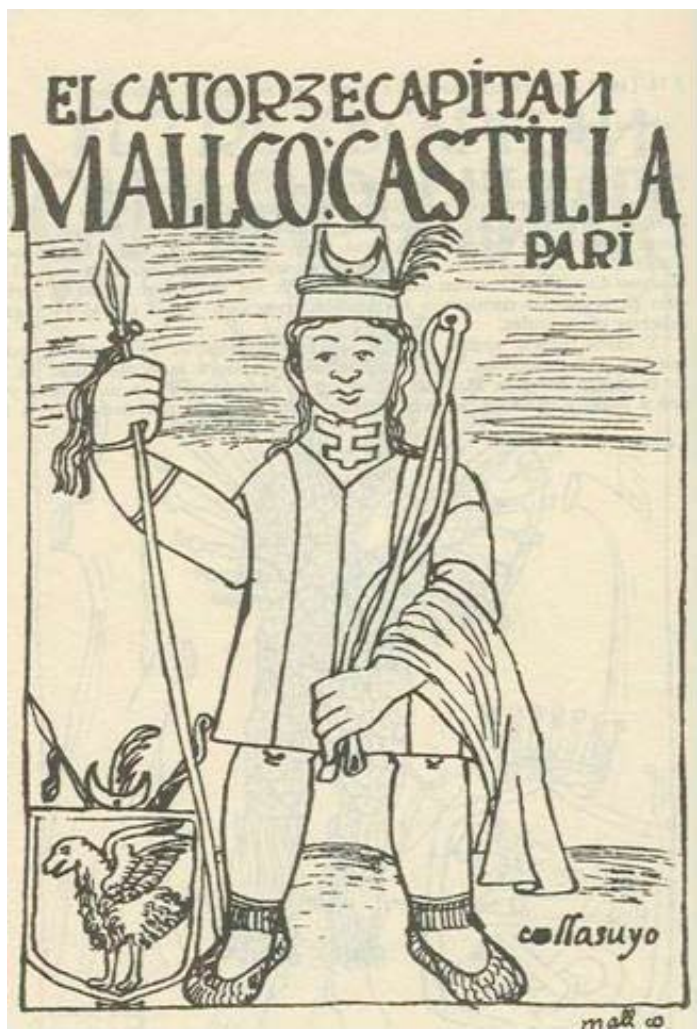

Figura 5. Capitán del Qullasuyu. Felipe Guaman Poma 1980 [1615/16], editado por J. Murra y R. Adorno. p. 148

Captain of the Qullasuyu. Felipe Guaman Poma 1980 [1615/16], edited by J. Murra and R. Adorno, p. 148.

sombreros y según Zuidema eran el emblema de la nobleza no-inka del Qullasuyu y su uso pervivió en la colonia (Figura 5)

Por otro lado, en los rituales y fiestas usaban unos vasos pequeños llamados vicchi con unos pies por donde salía la chicha y cocos o vasos (quero, aquillas) en forma de cubilete que usaban en pares para reforzar los vínculos de solidaridad o alianzas con wak'a o personas significativas ${ }^{28}$. Pero también tenían mucha plumería sobre todo el cacique de los Qulla y el de Totora (Tabla 5). Por ejemplo, el mallku Charka tenía collares de turquesas con plumas de juríes, coronas de plumas, y plumas amarillas y coloradas de guacamayas que hacían juego con sus textiles mientras que el mallku Qulla usaba sombreros redondos de plumas blancas y otros leonados llamados izanga (Figura 6), sombreros de plumas sin copa (guaraca), orejeras, empleando plumas de juríes, flamencos o guacamayas coloradas, azules y amarillas (Figura 6). También tenían "pillos 
Tabla 4. Adornos y objetos de los caciques por tipo de material. Cacique's adornments and objects by material type.

\begin{tabular}{|c|c|c|c|c|c|}
\hline \multirow{3}{*}{$\begin{array}{l}\text { Tipo de } \\
\text { material }\end{array}$} & \multirow{3}{*}{ Tipo de adornos } & \multicolumn{4}{|c|}{ Repartimento, Caciques, Cargo y Grupo Étnico } \\
\hline & & \multicolumn{3}{|c|}{ Pocona } & \multirow{2}{*}{$\begin{array}{c}\text { Totora } \\
\text { Pedro Xauxa, } \\
\text { (?- 1583), Cacique } \\
\text { principal, Charka }\end{array}$} \\
\hline & & $\begin{array}{l}\text { Pedro Chirima } \\
\text { (?- 1584), Cacique } \\
\text { (urin), Quta }\end{array}$ & $\begin{array}{c}\text { Juan Xaraxuri, (?- } \\
\text { 1580), Gobernador, } \\
\text { Quta }\end{array}$ & $\begin{array}{l}\text { Pedro Arapa, } \\
\text { (?-1574), Cacique } \\
\text { Principal, Qulla }\end{array}$ & \\
\hline \multirow{10}{*}{ Oro } & Anillo & & & 4 & \\
\hline & Chinico (1) & & & 5 & \\
\hline & Chipana & 1 & 1 & 5 & 1 \\
\hline & Choocho (2) & & & 2 & \\
\hline & Cocos & & 1 & & \\
\hline & Medallas & & & $3(4)$ & \\
\hline & Paure (3) & 1 & 1 & & \\
\hline & Pillo (5) & & 2 & 1 & \\
\hline & Turi & & 2 & & \\
\hline & Cadena con crucifijo & & & 1 & \\
\hline \multirow{22}{*}{ Plata } & Anillos & & & 4 & \\
\hline & Bacinilla (6) & & & 5 & \\
\hline & Chinico & & & 5 & \\
\hline & Chipana & 2 & 1 & $2(7)$ & 1 \\
\hline & Choocho & & & 2 & \\
\hline & Cocos (pares) (8) & 4 & 3 & 6 & \\
\hline & Colque hincho (9) & & & & 8 \\
\hline & Jarros (10) & & & 2 & \\
\hline & Medallas & & & 3 & \\
\hline & Paure & 2 & 4 & & \\
\hline & Pillos & 4 & & 3 & \\
\hline & Pinxes (11) & & & 11 & \\
\hline & Perco (12) & & & & 2 \\
\hline & Salero & & & 1 & \\
\hline & Sortijas & & & 4 & \\
\hline & Taguies & & & 2 & \\
\hline & Taraca/taracapis & & & & 4 \\
\hline & Taza (13) & & & 1 & 1 \\
\hline & Trompetas (14) & & & 2 & \\
\hline & Turi & 2 & 1 & & \\
\hline & Vasos conpies & & & 1 & \\
\hline & Vichos (15) & & & 4 & 1 \\
\hline \multirow{2}{*}{ Piedras } & Gualca o Collar & & & & $\begin{array}{l}1 \text { de turquesillas y } \\
\text { piedras verdes }\end{array}$ \\
\hline & & & & & $\begin{array}{c}1 \text { de cuentas azules y } 2 \\
\text { plumas de juries }\end{array}$ \\
\hline \multirow{4}{*}{ Estaño } & Escudillas & & & 3 & \\
\hline & Planchuelas & & & 10 & \\
\hline & Platos & & & 3 & \\
\hline & Turquíes & & & 17 & \\
\hline \multirow{3}{*}{ Madera } & Cascabeles & & & 4 & \\
\hline & Macana (16) & & & 1 & \\
\hline & Guantes & & & si & \\
\hline
\end{tabular}


Tabla 4 (continuación)

\begin{tabular}{|c|c|c|c|c|c|}
\hline \multirow{3}{*}{$\begin{array}{l}\text { Tipo de } \\
\text { material }\end{array}$} & \multirow{3}{*}{ Tipo de adornos } & \multicolumn{4}{|c|}{ Repartimento, Caciques, Cargo y Grupo Étnico } \\
\hline & & \multicolumn{3}{|c|}{ Pocona } & Totora \\
\hline & & $\begin{array}{l}\text { Pedro Chirima } \\
\text { (?- 1584), Cacique } \\
\text { (urin), Quta }\end{array}$ & $\begin{array}{l}\text { Juan Xaraxuri, (?- } \\
\text { 1580), Gobernador, } \\
\text { Quta }\end{array}$ & $\begin{array}{c}\text { Pedro Arapa, } \\
\text { (?-1574), Cacique } \\
\text { Principal, Qulla }\end{array}$ & $\begin{array}{c}\text { Pedro Xauxa, } \\
\text { (?- 1583), Cacique } \\
\text { principal, Charka }\end{array}$ \\
\hline \multirow{3}{*}{ Piel } & Pájaro & & & 2 cueros & \\
\hline & Víboras & & & $\begin{array}{c}\text { Cascabeles en plumas } \\
\text { de colores }\end{array}$ & \\
\hline & Tigre & & & & \\
\hline \multirow{2}{*}{ Colores } & Limpe (17) & & & 4 azeruelos & \\
\hline & Grana (18) & & & 7 panecillos & \\
\hline
\end{tabular}

Fuente: Testamento de don Juan Xaraxuri, de don Pedro Xauxa, de don Pedro Chirima y de don Pedro Arapa.

(1) También chuico, chevico, charico, chelico. Uno labrado con su medalla y un chuico con sus gualecas.

(2) Cchhokhcho: unas puntas de oro que solían adornar el sombrero (B:88).

(3) Paure o pariri: Media luna.

(4) "al uso de los indios".

(5) Pillo: Corona, guirnalda.

(6) Sirve de mate para beber.

(7) Brazalete mitad de oro y plata.

(8) Cocos: vasos a modo de cubilete, dos con pajarillas de oro y otros 2 con dos cintas con cintas de oro.

(9) Hinchu: la oreja (B:143).

(10) Uno llano con dos verdugos y otro labrado, ambos con pico.

(11) Colgantes para pillos.

(12) Torzal del hacha.

(13) Con una azanefa de flores y labrada por dentro.

(14) Trompeta, una volteada y otra llana. Derecha: quippa. Trompeta de vueltas: lo mismo (ST:221);

(15) Vicho: vichi: una ollita boquiancha donde echan la quinua o maíz mascado para chicha (B:384), mate grande para echar asua con caños en el pie por donde sale el asua.

(16) Arma con una hoja de plata de arriba hacia abajo.

(17) Linpe: lacdre para pintar. Lo guarda en una chuspa (B:212). Pastillas amasadas.

(18) Makhno: tortillas de yerbas que tiñen lanas coloradas (B:212). Pastillas amasadas con los cuerpos secos de la cochinilla para teñir. 
Tabla 5. Cantidad de adornos de plumas por cacique Amount of feather adornments by Cacique.

Tipo de adorno de plumas

\begin{tabular}{|c|c|c|c|c|}
\hline \multirow{3}{*}{ Tipo de adorno de plumas } & \multicolumn{4}{|c|}{ Repartimiento, Caciques, Cargo y Grupo Étnico } \\
\hline & \multicolumn{3}{|c|}{ POCONA } & \multirow{2}{*}{$\begin{array}{c}\text { TOTORA } \\
\text { Pedro Xauxa, } \\
\text { (?- 1583), Cacique } \\
\text { principal, Charka }\end{array}$} \\
\hline & $\begin{array}{l}\text { Pedro Chirima } \\
\text { (?- 1584), Cacique } \\
\text { (urin), Quta }\end{array}$ & $\begin{array}{c}\text { Juan Xaraxuri, (?- } \\
\text { 1580), Gobernador, } \\
\text { Quta }\end{array}$ & $\begin{array}{l}\text { Pedro Arapa , (?- } \\
\text { 1574), Cacique } \\
\text { Principal, Qulla }\end{array}$ & \\
\hline Apasus (flores de plumas) & & & 18 & \\
\hline Apsu pillo (Pillo de plumas) & & & & 3 \\
\hline Callapa blanca (1) & & & 2 & \\
\hline Callapa colorada & & & 1 & \\
\hline Caravayas de guacamaya aderezadas & & & & 15 \\
\hline Chambiguaichas de guacamayo & & & & 19 \\
\hline Escarana rojo amarillas & 10 & & & \\
\hline Escarana (Xicarana) de plumas & & & 3 & \\
\hline Guaraca (2) & & & 2 & \\
\hline Gualca (3) de chaquira y pluma & & & & 2 \\
\hline Izanga blanca & & & 1 & \\
\hline $\begin{array}{l}\text { Izanga(Xanga, azanga,asangalla) de guacamaya } \\
\text { leonado (4) }\end{array}$ & & & 11 & \\
\hline Manojos guacamayos & 3 & & & \\
\hline Orejeras (de plumas?) & & & 4 & \\
\hline Pajaros en petaca & & & 2 & \\
\hline Pariguana de plumas (5) & & & 2 & \\
\hline Penacho blanco de xuries & & & 1 & \\
\hline Penacho como clavelina & & & 2 & \\
\hline Penacho de guacamayo & & & 3 & \\
\hline Pillo ampara de guacamaya (6) & & & 1 & \\
\hline Pillo de pantaxa de pluma & & & 2 & \\
\hline Plumaje de estampillas & & & & 1 \\
\hline Plumas de guacamayas amarillas & & & & 27 \\
\hline Plumas de guacamayas coloradas & & & & 28 \\
\hline Plumas de guacamayas pequeñas & & & & 22 \\
\hline Plumas de xuries & & & & 1 \\
\hline Ticas con cascabeles de viboras (7) & & & 17 & \\
\hline Ticas coloradas y de otros colores & & & 8 & \\
\hline Ticas de guacamaya (azul, 2 a manera de ysopillos) & & & 20 & \\
\hline Ticas para bailar & & & 4 & \\
\hline Yunuris & 2 & & & 2 \\
\hline
\end{tabular}

Fuente: Testamento de don Juan Xaraxuri, de don Pedro Xauxa, de don Pedro Chirima y de don Pedro Arapa.

(1) K'allapa litera angarilla, parihuela, andas (L:114) v. kuyusmankko: sitial asiento de ceremonia. Varro en forma de trono.

(2) Huaraca: honda para tirar (GH:182 y 547). Sombrero sin copa para bailar.

(3) Huallcca: collar, cadena o sartal de cuentas y todo lo que se pone al cuello hombres y mugeres o bestias o animales etc. (GH:173) y (B:126).

(4) Assanco: plumaje de muchas plumas puestas en el sombrero redondo como capacete (B:371). Plumaje como escudilla (B:26).

(5) Pariwana: flamenco; pari huana paxaro flamenco (GH:279). Parina: Paxaro grande colorado que se cría en la laguna (B:251).

(6) Pillu Corona o cordón que usan algunas naciones de indios ponerse en la cabeza para apretar el cabello, deferente del que llaman llauto y cualquiera corona de flores o de oro para la cabeza (B 165).

(7) Ttica: la flor que es plumaje (GH:340). 


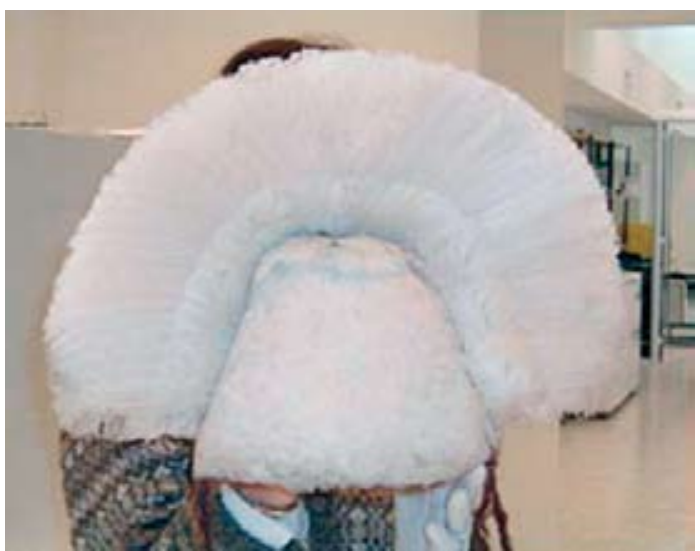

Figura 6. Sombrero de plumas. Museo Arqueológico de Alta Montaña, Salta.

Feathered hat. Museo Arqueológico de Alta Montaña, Salta.

ampara" de plumas de guacamayas que, junto a plumas sueltas, se usaban para bailar, en contextos festivos o para sus sacrificios mientras que con otras plumas adornaban sus hondas o les ponían cascabeles de víboras (amaru, símbolo del arco iris) en sus extremos (Yacovleff 1933:137-158) ${ }^{29}$. Nuevamente como en el caso de los textiles había símbolos muy extendidos en los Andes como los queros, las chipanas, orejeras y plumas pero otros como las medias lunas que estaban restringidos a los guerreros del Qullasuyu.

Es evidente que se nos escapan las resignificaciones que tuvieron estas prendas en el contexto regional y en qué momentos y para qué fueron utilizadas. Es posible que sirvieran para demostrar el alto estatus de los caciques y para trazar o marcar líneas vinculantes con personajes importantes del pasado y reforzar los lazos de solidaridad entre los miembros de sus ayllus.

Sin duda todas ellas aluden al tiempo del inka, pero no se trata tan solo de una referencia a los gobernantes cusqueños sino de una estética propia de las dinastías provinciales del Qullasuyu que recuerda a los prestigiosos capitanes y líderes regionales locales tanto de Charcas como de Pocona que estuvieron como esta historia quiso esbozar, prestigiosamente vinculados a la estructura administrativa estatal.

Agradecimientos: Quisiera agradecer las valiosas recomendaciones de los evaluadores que permitieron mejorar este trabajo. Asimismo, las reflexiones de Verónica Cereceda, Thérèse Bouysse-Cassagne, Ángeles Muñoz y Verónica Williams que enriquecieron mi comprensión de los testamentos.

\section{Referencias Citadas}

\section{Documentos inéditos}

AHMC-MEC

Archivo Histórico Municipal de Cochabamba, Colección de Mizque, Expedientes Coloniales. AHP

Archivo Histórico de Potosí.

AHMC-MEC 1 Testamento de don Juan Xaraxuri (Pocona 1580).

AHMC-MEC 1 Testamento de don Pedro Arapa (Pocona 1574).

AHMC-MEC 1 Testamento de don Pedro Xauxa (Totora 1583).

AHMC-MEC 1 Testamento de don Pedro Chirima (Pocona 1584).

Albornoz, C. de

1989 [1581-1584] Instrucción para descubrir todas las guacas del Perú y sus camayos y haciendas. En Fábulas y Mitos de los Incas, editado por H. Urbano y P. Duviols. Historia 16, Madrid.

Alconini, S.

2002 Prehistoric Inka Frontier Structure and Dynamics in the Bolivian Chaco. Doctoral Dissertation. University of Pittsburgh, Pittsburgh.
Barragán, R.

1994 Indios de Arco y Flecha. ASUR, Sucre.

Bertonio, L.

1984 [1612] Vocabulario de la Lengua Aymara. CERES/ IFEA/MUSEF, Cochabamba.

Betanzos, J. de

1987 [1551] Suma y Narración de los Incas Capacruna que fueron Señores de la Ciudad de Cuzco y de todo lo a ella Subjetado. Atlas, Madrid.

Blanco, F

2003 [1910] Diccionario Geográfico del Departamento de Cochabamba. CERES-UMSA, Cochabamba.

Cieza de León, P.

1991 Crónica del Perú. Cuarta Parte. Guerra de Las Salinas. PUCP, Lima.

Clark, N.R.

1993 Glossary of Textile Terminology. The Estuquiña Textile Tradition. Doctoral Dissertation, Washington University. St. Louis.

Cobo, B.

1964 [1653] Historia del Nuevo Mundo. Atlas, Madrid.

Cummins, $\mathrm{T}$.

1998 Let me see! Writing is for them. Colonial Andean images and objects: "como es costumbre tener los caciques Señores". En Native Traditions in the Postconquest World, 
editado por E. Boone y T. Cummins, pp. 91-148. Dumbarton Oaks, Washington D.C.

Gisbert, T., S. Arce y M. Cajias 1992 Arte Textil y Mundo Andino. Editorial TEA, Buenos Aires.

Gonzalez Holguin, D.

1989 [1608] Vocabulario de la Lengua General de Todo el Perú Llamada Lengua Qquichua. Universidad Mayor de San Marcos, Lima.

Gordillo, J. y M. del Río

1993 La Visita de Tiquipaya. UMSS-CERES, Cochabamba.

Guaman Poma, F.

1980 [1615/16] El Primer Nueva Coronica y Buen Gobierno, editado por J. Murra y R. Adorno. Siglo XX, México.

Julien, C.

1998 Coca Production on the Inca Frontier the yungas of Chuquioma. Andean Past 5:129-159.

Lechtman, $\mathrm{H}$.

1975 Issues in Andean Metallurgy. En Pre-Columbian Metallurgy of South America, editado por E.P. Benson, Lira, J. pp. 1-40. Dumbarton Oaks, Washington D.C.

1982 Diccionario Kkechuwa-Español. Editora Guadallupe, Bogotá.

Medinacelli, X. y P. Mendieta

1997 De Indias a Doñas. Mujeres de la Elite Indígena en Cochabamba, Siglos XVI-XVII. Ministerio de Desarrollo Humano, La Paz.

Meruvia Valderrama, F.

2000 Historia de la Coca. Los Yungas de Pocona y Totora (1550-1900). Plural, CERES, Alcaldía de Totora, La Paz.

Muñoz, M.

2006 Patrimonio cultural y desarrollo local comunitario: el caso de Incallajta. Cuadernos de Investigación 1. Universidad Mayor de San Simón, Cochabamba.

Murra, J., editor

1991a Visita de los Valles de Sonqo en los Yunka de Coca de La Paz (1568-70). Instituto de Cooperación Iberoamericano, Instituto de Estudios Fiscales, Madrid.

Murra, J.

1991b Introducción al estudio histórico del cultivo de la hoja de coca [Exythroxylon coca] en los Andes. En Visita de los Valles de Sonqo en los Yunka de Coca de La Paz (1568-70), editado por John Murra, pp. 565-581. Instituto de Cooperación Iberoamericano, Instituto de Estudios Fiscales, Madrid.

1991c Los Cultivadores Aymara de la Hoja de Coca: dos Disposiciones Administrativas [1568-70]. En Visita de los Valles de Sonqo en los Yunka de Coca de La Paz (156870), editado por John Murra, pp. 653-674. Instituto de Cooperación Iberoamericano, Instituto de Estudios Fiscales, Madrid.

Murúa, M. de

1987 [1615] Historia General del Perú, editada por Manuel Ballesteros. Historia 16, Madrid.

2004 [1615] Códice Murúa: historia y genealogía de los reyes incas del Perú del padre mercedario Fray Martín de Murúa: códice Galvin, estudio de Juan Ossio. Testimonio Compañía Editorial, Madrid.

Pärssinen, M. y A. Korpisaari

2003 Western Amazonia-Amazonia Occidental. Renvall Institute for Area and Cultural Studies, Helsinki.
Pizarro, P.

1986 Relación del Descubrimiento y Conquista de los Reinos del Perú. PUCP, Lima.

Platt, T., T. Bouysse-Casagne y O. Harris

2006 Qaraqara-Charka. Mallku, Inka y Rey en la Provincia de Charcas (siglos XV-XVII). Historia Antropológica de una Confederación Aymara. Plural editores, Instituto Francés de Estudios Andinos, Fundación Cultural del Banco Central de Bolivia, University of St. Andrews, La Paz.

Polo de Ondegardo, J.

1990 [1571] Notables Daños de no Guardar a los Indios sus Fueros. En El Mundo de los Incas, editado por L. González y A. Alonso. Historia 16, Madrid.

Ramírez Valverde, M.

1970 [1557] La Visita a Pocona, 1557. En Historia y Cultura. Museo Nacional de Historia, Lima.

Renard-Casevitz, F.M., T. Saignes y A.C. Taylor

1988 Al Este de los Andes. Relaciones entre las Sociedades Amazónicas y Andinas entre los Siglos XV y XVII. AbyaYala/IFEA, La Paz.

Rowe, J.

1973 Standarization in Inca tapestry tunics. En The Junius B. Bird Pre-Columbian Textile Conference, editado por A. Rowe, E. Benson y A. Schaffer, pp. 239-264. Dumbarton Oaks, Washington D.C.

1985 Probanza de los Incas nietos de conquistadores. Histórica IX. Vol.2:193-245.

Saignes, T.

1985 Andes Orientales. Historia de un Olvido. IFEA/CERES, Cochabamba.

Santo Tomás, D.

1951 Lexicón o Vocabulario de la Lengua General del Perú, editado por R. Porras Barrenechea. Instituto de Historia, Lima.

Santos Escobar, R.

1987 La Contribución de Apu ChalcoYupanki, Gobernador del Kollasuyu en la Expedición de Diego de Almagro a Copiapó, Principio de Chile. En Colección de Folletos Bolivianos de Hoy. Vol iii, 24.

Sarmiento de Gamboa, P.

1943 [1572] Historia General Llamada Indica. Emecé Editores S.A., Buenos Aires.

Schramm, R.

1990a Mosaico etnohistórico del Valle de Cliza (Alto Cochabambino) Historia y Cultura 16:41.

1990b Introducción. En Visita de los Yndios Churumatas e Yndios Charcas de Totora que todos están en Cabeza de Su Magestad de Juan González. MUSEF, La Paz.

1995 Fronteras y Territorialidad. Repartición étnica y política colonizadora en los Charcas (Valles de Ayopaya y Mizque). En Espacios, Etnias, Fronteras, editado por A.M. Presta, pp. 163-218. Ediciones ASUR, Sucre.

1999 Pocona und Mizque: Die Umgestaltungeiner indianischen Gesellschaft in Kolonialen Peru (Charcas). Köln,Wemar, Wien. Böhlau. Lateinamerikanische Forschungen 27.

Siiriäinen, A y M. Pärssinen

1997 Eighty years after Erland Nordenskiöld: The question of the eastern frontier of the Inca Empire in Bolivia. Artikkelit Huhtikuu (abril).http://www.helsinki.fi/hum/ibero/xaman/ articulos/9704/9704_sp.html (3 diciembre 2006). 
Yacovleff, E.

1933 Arte plumaria entre los antiguos peruanos. Revista del Museo Nacional. Tomo II; Vol. 2:137-158.

Wachtel, N.

1981 Los mitimas del valle de Cochabamba: la política de colonización de Wayna Capac. En Historia Boliviana $\mathrm{I} / 1: 21-57$.
Zuidema, T.

1991 Guaman Poma and the Art of Empire: Toward an Iconography of Inca Royal Dress. En Transatlantic Encounters. Europeans and Andean in the Sixteenth Century, editado por K. Andrien y R. Adorno, pp. 151-202. University of California Press, Berkeley.

Notas

1 La versión de Sarmiento de Gamboa, afirma que "[Wayna Qhapaq] Fué al valle de Cochabamba y hizo alli cabecera de provincia de mitmaqkuna de todas partes, porque los naturales eran pocos y habia aparejo para todo, en que la tierra es fertil. Y de alli fue a Pocona a dar orden en aquella frontera contra los Chiriguanaes y a re[e]dificar una fortaleza que habia hecho su padre (Rowe 1985:124). Según Juan de Betanzos “...llego al pueblo de Cochabamba que es ciento sesenta leguas de la ciudad del Cusco y como alli llegase vio y visitó las guarniciones de gente que su padre Topa Ynga Yupanque en aquella provincia y sus comarcas había dejado..." (Betanzos 1987 [1551]:I:192). Ver también: Bernabé Cobo 1964 [1653]: Libro 12:14:85; Murúa 1987[1615]:109).

2 AHMC-MEC Testamento de Juan Jarajuri. Según Schramm (1999:200), Turumaya era de nación Huanca.

3 Raimund Schramm, apoyándose en una excelente prospección documental, analizó con mucho detalle los vínculos y movimientos de los diferentes grupos de estos valles interiores tanto prehispánicos como coloniales. Barragán sugiere que los Chuiy de Jarajuri pudieron englobar a varios grupos étnicos y señala los fuertes vínculos con los Quta, también apuntado por Raimund Schramm. Muchas de sus conclusiones han inspirado esta contextualización.

4 Las chacras de Kuysara eran Payrumani, Chuquioma, Laymitoro, Sipsipampa, Cataquila, Lequeleque, Tontoni, Apacheta, Cantani y Charupampa. AGI Justicia 428, citado por Julien 1998. Por su parte Moroco tenía unos 17 indios en Tiraque.

5 El cuarto presupuesto, ....en cada uno dividió las tierras en esta forma: una parte dellas aplicó para la religión ... dividió por ceques y rayas la comarca e hizo adoratorios de diversas advocaciones, todas las cosas que parecian notables de fuentes, manantiales y puquios y piedras ondas y valles y cumbres quellos llaman apachetas e puso a cada cosa su gente e les mostró la orden que habían de tener en sacrificar cada una de ellas, y para que efecto, y puso quien se lo enseñase y en que tiempo y con que género de cosas...e vista la carta de las guacas del Cuzco en cada pueblo por pequeño que sea la pintaron de aquella misma manera y mostraron los ceques y guacas y adoratorios fijos que para saverlo es negocio importantísimo para su conversión, que yo la tengo ensayada en mas de cien pueblos y el Señor Obispo de los Charcas dudando el si aquello fuese tan universal, cuando vinimos juntos al negocio de la perpetuidad por mandado de Su Majestad se lo mostré en Pocona y los mismos indios le pintaron alli la misma carta y en esto no hay duda... (Polo de Ondegardo 1990 [1571]:47).

6 Dicho Cumsara y un Inca que estaba puesto por gobernador a guarda de las fortalezas de esta provincia como señor tan grande y criado del Inca principal, señor deste reino, y un Ausita [Sora] estos solos fueron los que traian lanpas, por ser como eran los mayores de esta provincia..." (Platt et al. 2006:935).

7 Los capitanes convocaban a los hatunrunas para el servicio militar y como afirma Polo era una: “...contribución muy pesada y ordinaria de dar gente para la Guerra...; tuvieron despues necesidad de tener fronteras ...en todas estas partes hallamos el dia de oy los Pucaraes e fuertes adonde se recogia la gente e caminos hechos hasta la tierra de Guerra del cual servicio ninguno se reservaba... y en muchas provincias estaba la gente de asiento, como Mitimaes de todas las naciones como en Pocona y en otras partes donde se quedaron y encomendaron ansi como los hallamos..." (Polo de Ondegardo 1990 [1571]:87).

8 En esta línea se pueden ubicar Inkallajta y un poco más al sur Oroncota, Incahuasi, Incapirca e Iñao

9 La probanza de don Juan Ayawiri se puede identificar a esos capitanes como pertencecientes a los Charka, Qaraqara, Killaka, Karanqa, Sura, Chicha, Yampara, Chuy y mitmaqkuna de Pocona. De esta zona destacan la presencia de Jarajuri, cacique de los Chuis y don Hernando Turumaya por los mitmaqkuna de Pocona.

10 “...e algunos sacerdotes de sus tenplos que entre ellos venyan ynvocaban al demonio para que les diese ayuda e al sol hazian muchos sacrificios e trayan algunos dioses hechos de metal de plata y oro e de palo delante de los cuales hacian grandes esclamaciones ofreciendose hazer grandes sacrificios en sus templos o guacas....aquella noche hizieron grandes fuegos... comer e beber..." (Cieza de León 1991:281-282).

11 Pedro de Valdivia obtuvo del marqués Francisco Pizarro un depósito en el valle de la Canela (Pocona y Mizque). Sin embargo, rápidamente abandonó esta merced siendo reasignada la encomienda al fundador de la Villa de La Plata, Pedro de Anzurez y a su hermano Gaspar Rodriguez (1539). Luego, durante el gobierno de Vaca de Castro (1541-1544), la encomienda se reasignó a Diego Centeno, Dionisio de Bobadilla y Lope de Mendoza. Seguidamente, La Gasca dividió la población del valle de la Canela entre Hernández Paniagua (Mizque) y el capitán Gómez de Alvarado (Pocona). A su muerte pasó a Francisco de Mendoza cuya viuda mantuvo un concierto con la Corona hasta 1575. En cuanto a Totora, sus encomenderos fueron entre otros Gómez de Luna y Luis Perdomo, luego se sumaron Diego de Villavecencio y Hernán Pérez de Párraga.

12 AHP Caja Real 1.

13 Estos números son los que figuran al final de la visita. Entiendo que son aproximados ya que los datos en yungas son generales (no casa por casa) y no están desagregados por grupos de edad. 
14 AHMC-MEC.Testamento de don Pedro Chirima.

15 Los caciques a cargo de Turumaya eran don Miguel Gualla, don Pedro, don Francisco Vilcachawa y don Francisco.

16 Para un análisis etnohistórico de la producción cocalera regional consultar Catherine Julien 1998 y Meruvia Valderrama 2000.

17 Según Blanco (2003:185), el asentamiento original se hallaba a una legua del actual Pocona y en las inmediaciones de Layminia, el cual fue destruido en el siglo XIX por los Yurakarés.

18 El valle de Conda está situado a una legua y media del tambo de Pocona.

19 A.H.M.C. "Testamento de don Pedro Arapa, 1574".

20 En la visita de 1556, don Tomas Caua, cacique de avanzada edad de los Qulla, destacaba que había heredado de su padre una chacra en los cocales.

21 Don Carlos Inka era hijo de Pawllu y había recibido la encomienda de Pichigua-hatun Cana y Yarue (Prov. de los Canas) en 1549. Fue arrestado en 1572 por una presunta alianza con los de Vilcabamba y puesto en libertad por el Rey. Murió en 1582.

22 A.N.B. EP Bravo 10/9/1572: En Pocona y Arabate hay indios sujetos a don Alonso Molo Arcaya, cacique de la encomienda de Miguel Almazan, vecino de Arequipa (son Kuntisuyus de Andagua y Chachas).

23 A.H.M.C. Mizque Expedientes Coloniales, 1. "Testamento de don Pedro Xauxa".

24 Se trata de mitmaqkuna Icayungas.

25 En los Andes, había buenos especialistas en estas labores como fueron los Qulla de Capachica y los Chupaichos.

26 En su testamento se menciona cada una de las combinaciones de manta y camiseta usadas por el mallku. En los cuadros se ha respetado el orden de estos pares de prendas.
27 “....asi mismos se a de tirar y destruir... y de los capitanes valerosos que a avido entre ellos, como son sus vestido ajedrezados o con culebras pintadas que llaman amaros o alguna porra de guerra que llaman chambi o algun caracol que suena como trompeta o alguna lanza o adarga... porque la reverencian y mochan" (Albornoz 1989 [15811584]:172).

28 Según Pedro Pizarro "Tenian tambien delante de estos muertos unos canxilones grandes (que ellos llaman birques [vicchi]) de oro u de plata u de barro cada uno como queria y aqui echaban la chicha que al muerto le daban, mostrándosela combidándose unos muertos a otros y los muertos a los bivos y los bivos a los muertos. Pues llenos estos birques los derramaban en una piedra redonda que tenían por idolo, en mitad de la plaza y hecha alrededor una alberca pequeña donde se consumia por unos caños que ellos tenian echos por debaxo de la tierra" (Pizarro 1986:89).

29 "Sobre las vestiduras ordinarias se ponían sus galas y atavíos cuando iban a la guerra, y en los regocijos y fiestas solemnes. Los más de estos arreos eran de plumas de varios y vistosos colores" (Cobo 1964 [1653]: Libro 14: cap. II y cap. XI). Polo decía que "también sacrificaban plumas de diversos colores en especial coloradas y amarillas traydas de los Andes llamadas Paucar pillco parihuana”. También quemaban las plumas de los pájaros de la puna cuando iban a la guerra a fin de disminuir la fuerza de las huacas contrarias (Polo de Ondegardo 1990 [1571]:39).

La guaraca era un arma defensiva utilizada para la guerra por los escuadrones de honderos del ejército inca. La honda también tenía un uso ritual. La usaban las divinidades como Illapa en los Andes del Sur, para producir truenos, rayos y relámpagos y por ende para producir granizos, lluvias y tormentas. 